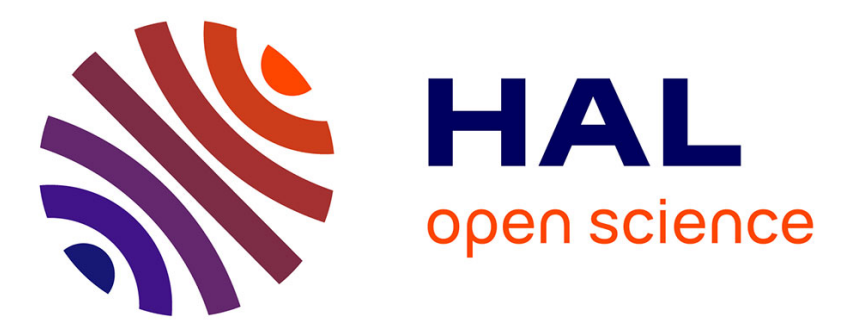

\title{
Investigation of the Effect of Residual Stress Gradient on the Wear Behavior of PVD Thin Films
}

\author{
Brahim Tlili, Corinne Nouveau, Gildas Guillemot, Aurélien Besnard, A. \\ Barkaoui
}

\section{- To cite this version:}

Brahim Tlili, Corinne Nouveau, Gildas Guillemot, Aurélien Besnard, A. Barkaoui. Investigation of the Effect of Residual Stress Gradient on the Wear Behavior of PVD Thin Films. Journal of Materials Engineering and Performance, 2018, 27 (2), pp.457-470. 10.1007/s11665-018-3132-1 . hal-01695338

\section{HAL Id: hal-01695338 \\ https://hal-mines-paristech.archives-ouvertes.fr/hal-01695338}

Submitted on 9 Mar 2018

HAL is a multi-disciplinary open access archive for the deposit and dissemination of scientific research documents, whether they are published or not. The documents may come from teaching and research institutions in France or abroad, or from public or private research centers.
L'archive ouverte pluridisciplinaire HAL, est destinée au dépôt et à la diffusion de documents scientifiques de niveau recherche, publiés ou non, émanant des établissements d'enseignement et de recherche français ou étrangers, des laboratoires publics ou privés. 


\title{
Investigation of the Effect of Residual Stress Gradient on the Wear Behavior of PVD Thin Films
}

\author{
B. Tlili, C. Nouveau, G. Guillemot, A. Besnard, and A. Barkaoui
}

\begin{abstract}
The control of residual stresses has been seldom investigated in multilayer coatings dedicated to improvement of wear behavior. Here, we report the preparation and characterization of superposed structures composed of $\mathrm{Cr}, \mathrm{CrN}$ and $\mathrm{CrAIN}$ layers. Nano-multilayers $\mathrm{CrN} / \mathrm{CrAIN}$ and $\mathrm{Cr} / \mathrm{CrN} / \mathrm{CrAIN}$ were deposited by Physical Vapor Deposition (PVD) onto Si (100) and AISI4140 steel substrates. The Cr, CrN and CrAIN monolayers were developed with an innovative approach in PVD coatings technologies corresponding to deposition with different residual stresses levels. Composition and wear tracks morphologies of the coatings were characterized by scanning electron microscopy, high-resolution transmission electron microscopy, atomic force microscopy, x-ray photoelectron spectroscopy, energy-dispersive x-ray spectroscopy, $x$-ray diffraction and 3D-surface analyzer. The mechanical properties (hardness, residual stresses and wear) were investigated by nanoindentation, interferometry and micro-tribometry (fretting-wear tests). Observations suggest that multilayer coatings are composed mostly of nanocrystalline. The residual stresses level in the films has practically affected all the physicochemical and mechanical properties as well as the wear behavior. Consequently, it is demonstrated that the coating containing moderate stresses has a better wear behavior compared to the coating developed with higher residual stresses. The friction contact between coated samples and alumina balls shows also a large variety of wear mechanisms. In particular, the abrasive wear of the coatings was a combination of plastic deformation, fine microcracking and microspallation. The application of these multilayers will be wood machining of green wood.
\end{abstract}

Keywords friction, hardness, PVD coatings, residual stresses, structure, wear

\section{Introduction}

The deposition of hard coatings by PVD, based for example on chromium or aluminum nitride, is considered as one of the most promising ways to improve the wear behavior of tools (Ref 1,2$)$. In addition, one can note that the use of a singlelayer coating is not efficient enough when considering some specific working environments (e.g., thermo-chemical conditions) even using binary, ternary or more complex compositions (Ref 3, 4). Consequently, the research is yet focused on multilayer systems and the optimization of their deposition conditions in order to improve the mechanical and tribological properties (Ref 3-5). These coatings are made up of two or three different layers. Generally, these layers are composed of metallic elements, carbides or nitrides. Oxides of various other elements are also used in such applications. The thickness of

B. Tlili and A. Barkaoui, LR-11-ES19 Laboratoire de Mécanique Appliquée et Ingénierie (LR-MAI), Université de Tunis El Manar, Ecole Nationale d'Ingénieurs de Tunis, 1002 Tunis, Tunisia; C. Nouveau and A. Besnard, Arts et Métiers ParisTech - LaBoMaP, Campus Arts et Métiers ParisTech de Cluny, Rue Porte de Paris, 71250 Cluny, France; and G. Guillemot, CEMEF-Centre de Mise en Forme des Matériaux, CNRS, UMR 7635, CS10207, MINES ParisTech, PSL Research University, 06904 Sophia Antipolis, France. Contact e-mails: tlilii_brahim@yahoo.fr, corinne.nouveau@ensam.eu, gildas.guillemot@mines-paristech.fr, aurelien.besnard@ensam.eu, and aabarkaoui@gmail.com.

each individual layer evolves from few nanometers up to one micrometer. A couple of layers can also be proposed where the first layer is made of carbide, nitride and oxide of a single metal, whereas the second layer is made of another metal compound (Ref 6).

In the literature, studies of various coatings systems, such as $\mathrm{Cr} / \mathrm{CrN}$ (Ref 7), CrN/CrAlN (Ref 8, 9) and TiAlN/TiN (Ref 10) are regularly reported. These coatings have been largely investigated and accurately studied. The results obtained were compared with the constituent monolayer coatings, and a strong difference was always reported (Ref 11,12$)$. This difference is probably related to the effect of interfaces and their interactions. The CrN coatings have been used under different metallurgical phases to improve the lifetime of wood cutting tools, molding dies and machine parts. However, these coatings exhibit poor resistance to oxidation at large temperature higher than $600{ }^{\circ} \mathrm{C}$ (Ref 13-16). The thermal stability of the hard coatings is of primary importance; especially in machining processes where the coated tool can be exposed to high temperatures for the period of cutting. The resistance to oxidation at large temperatures has also an important influence in the wear resistance. Therefore, various studies have shown that addition of aluminum to the binary $\mathrm{CrN}$ layer allows working at high temperatures without any occurrence of oxidation (Ref 13-15). The CrAIN ternary layers were reported to be stable and well controlled at $900{ }^{\circ} \mathrm{C}$ depending on the aluminum content in the coatings (Ref 15, 16). Higher hardnesses associated with low friction coefficients were also observed (Ref 16, 17) compared to single binary $\mathrm{CrN}$ layer when considering addition of aluminum. However, the addition of a third transition element in a nitride coating usually leads to an increase in the residual stresses (Ref 18, 19). Indeed, residual stress is higher for the ternary $\mathrm{CrAlN}$ coating than for the binary $\mathrm{CrN}$ one. 
Many reports have stated that a solid solution with lattice distortions is generally formed when the aluminum content is below $\sim 77$ at.\% (Ref 19-24). Hence, it appears that the structure of the Al-containing coatings is in a metastable state, where $\mathrm{Al}$ atoms could substitute the $\mathrm{Cr}$ atoms in the f.c.c.- $\mathrm{CrN}$ lattice as suggested by Ref 20-22. The $\mathrm{Cr}$ atoms could equally substitute the $\mathrm{Al}$ atoms in the f.c.c.-AlN lattice as described by Reiter et al. (Ref 21). Several authors suggested that AIN forms solid solutions with chromium when the deposition process is far from the equilibrium conditions (Ref 21, 22). This structural state favors the formation of lattice defects during deposition, indicating a complex columnar microstructure with imperfections that are related to the deposition process (porosity, continuity defects, nanostratification features...). The grain size of CrAlN structure is also quite small and estimated between $10 \mathrm{~nm}$ and $20 \mathrm{~nm}$ (Ref 20, 21). Moreover, grain boundaries play an important role in the elastic and elastoplastic deformation in polycrystalline structures parts. This role is at the origin of the heterogeneous deformations observed in grains. Consequently, incompatibilities of plastic deformation induce internal stresses in the grains. These latter can be considered as inhomogeneous at the grain scale and may relax by plastic deformations. Therefore, local internal stresses and deformations are closely related. Thereafter, they have also a large influence on the behavior of CrAlN layers submitted to stress and damage under real work conditions.

According to many investigations reported in the literature (Ref 20-23), the CrAlN films have good mechanical properties and show a large oxidation resistance due to their solid solution structure (Ref 21). However, most of the physicochemical and mechanical properties of these hard films are influenced by several factors (current intensity, vacuum, time...), such as deposition process conditions (Ref 21-24). Most of the studies and researches have been focused on the development of PVD coatings. Nevertheless, few of them investigated the residual stresses influence based on the addition of a transition metal to the binary $\mathrm{CrN}$ layer. However, this addition may have a positive effect leading simultaneously to an improvement of the tribological performance and an increase of the wear resistance for multilayer coatings. In previous studies (Ref 22, 24), the mechanical and physicochemical properties of CrAlN-based multilayer coatings were investigated, without discussing the level of residual stresses, neither their influence on the microstructure. Similarly, the structure, the friction behavior or the wear resistance were not subject of interest. However, Clyne et al. (Ref 24) have noted that stress distributions in thick coatings rarely correspond to the presence of such a uniform misfit strain, so that recourse to numerical methods becomes essential for quantitative prediction of stress distributions. Relationships are presented between residual stresses and corresponding strain energy release rates during interfacial debonding (Ref 24). Ahlgren et al. (Ref 25) studied the effect of residual stress in TiAlN coatings deposited on cutting tools. The phenomenon of coating delamination from the substrate is discussed as well as its effect on the lifetime of the tool. The substrate polarization influence is considered as a main parameter affecting the residual stresses and the coating texture. Moreover, Djouadi et al. (Ref 19) have studied the influence of the film thickness on the compressive stresses as well as on the mechanical and structural properties of $\mathrm{CrN}$ and $\mathrm{Cr}_{2} \mathrm{~N}$ films. The results show that for both phases, the stress level depends of the film thickness. It is also demonstrated that these films are stable when heated to temperatures up to $727^{\circ} \mathrm{C}$.
Thereby, these previous studies led the authors to the investigation of $\mathrm{CrN} / \mathrm{CrAlN}$ and $\mathrm{Cr} / \mathrm{CrN} / \mathrm{CrAlN}$ thin films in which the $\mathrm{Cr}, \mathrm{CrN}$ and $\mathrm{CrAlN}$ layers properties are combined with different levels of residual stresses. The method detailed below is original since it has not been proposed in previous studies reported in the literature. In the present approach, large experimental investigations have been carried out to develop a new generation of chromium-based coatings. Indeed, binary $(\mathrm{CrN})$, ternary (CrAlN) monolayers, as well as $\mathrm{CrN} / \mathrm{CrAlN}$ multilayers with or without a chromium-bonding layer, were produced. The relationship between microstructure, friction, mechanical properties and residual stress gradient is established and discussed. The role of the chromium underlayer and the performance of the multilayer coatings was also a subject of interest. After a detailed presentation of the deposited coatings and the characterization methods, the enhanced properties of the coated samples will be highlighted in order to show the benefits of these new process conditions. The overriding goal of our research is the development of a new protective coating system to improve tools service life.

\section{Experimental}

\subsection{Deposition Technology}

The coatings were deposited on mechanically polished steel AISI 4140 (Ref 23), which measured roughness $\left(R_{a}=0.03 \mu \mathrm{m}, R_{t}=0.11 \mu \mathrm{m}\right)$ and silicon (100) samples $\left(10 \times 10 \mathrm{~mm}^{2}, 0.38 \mathrm{~mm}\right.$ thick $)$ using a RF confocal dual magnetron sputtering system with high purity targets $(\mathrm{Cr}$ of $99.95 \%$ and $\mathrm{Al}$ of $99.99 \%$ ). The samples were ultrasonically cleaned in acetone followed by de-ionized water. Both samples and targets were in situ etched in pure argon plasma during 15 min with argon pressure around $2.10^{-5}$ mbar. In order to improve the corrosion resistance and adhesion of the total layer (Ref 22), a chromium underlayer of different thicknesses evolving between 47 and $860 \mathrm{~nm}$ was deposited. This thickness evolution was dedicated to determine the maximum residual stresses in the underlayer, as well as their influence on the film adhesion. The target-to-substrate distance was about $100 \mathrm{~mm}$, with an angle close to $45^{\circ}$ for each target. High purity nitrogen gas (99.999\%) was injected into the vacuum chamber as a reactive gas, in the proportion of $20 \%\left(\mathrm{~N}_{2}\right)$ when nitrogen atoms are used to develop $\mathrm{CrN}$ or CrAlN layers. The residual pressure was about $10^{-7}$ mbar. The target shutters were moved at variable time delays in order to obtain the different $\mathrm{Cr} / \mathrm{Al}$ ratios of the layers. The samples were not heated during or after the deposition process preventing any temperature effect on phase evolutions. The plasma temperature was always lower than $200{ }^{\circ} \mathrm{C}$. The total thickness of the $\mathrm{Cr} / \mathrm{CrN} / \mathrm{CrAlN}$ and CrN/CrAlN multilayer coatings ranged from 256 to $1500 \mathrm{~nm}$, measured on SEM cross sections. The Table 1 summarizes the deposition parameters: Target bias voltage, deposition time and gas mixture for both mono- and multilayers. Three types of monolayer were studied corresponding to $\mathrm{Cr}, \mathrm{CrN}$ and $\mathrm{CrAlN}$ coatings. The six multilayer coatings are developed by the realization of several layers $(\mathrm{Cr}, \mathrm{CrN}$ or $\mathrm{CrAlN})$ in specific process conditions. These conditions correspond to the development of maximum (hereafter-denoted $P_{c}$ : maximum) or stable (hereafter-denoted $P_{t}$ : stable) residual stresses in the layer. Indeed, the residual stresses in the coating depend on the layer thickness with a non-monotonous evolution. Some 
specific thicknesses hereafter named $P_{t}$ lead to stable values in residual stresses. Some other deposited thicknesses lead to a sudden variation in same stresses before stabilizing again. These specific thicknesses are hereafter named $P_{c}$. The stresses related to these thicknesses $\left(P_{c}\right.$ and $\left.P_{t}\right)$ correspond to specific monolayer thicknesses used to develop the multilayer coatings. Thicknesses corresponding to both specific residual stresses $\left(P_{c}\right.$ and $P_{t}$ ) have been separately estimated in the preliminary monolayer experiments before secondary experiments dedicated to multilayer coatings. The process parameters leading to these levels of residual stresses are determined separately, as detailed hereafter. All the multilayer coatings are rated by $\mathrm{PVD}_{\mathrm{i}}$. Properties and characteristics of six specific coatings have been investigated corresponding to the following combinations:

$$
\begin{aligned}
& \text { PVD }_{1}:(\mathrm{CrN} / \mathrm{CrAlN}) P_{t} / P_{t} \\
& \text { PVD }_{2}:(\mathrm{Cr} / \mathrm{CrN} / \mathrm{CrAlN}) P_{t} / P_{t} / P_{t} \\
& \text { PVD }_{3}:(\mathrm{CrN} / \mathrm{CrAlN}) P_{c} / P_{c} \\
& \text { PVD }_{4}:(\mathrm{Cr} / \mathrm{CrN} / \mathrm{CrAlN}) P_{c} / P_{c} / P_{c} \\
& \text { PVD }_{5}:(\mathrm{CrN} / \mathrm{CrAlN}) P_{t} / P_{c} \\
& \text { PVD }_{6}:(\mathrm{Cr} / \mathrm{CrN} / \mathrm{CrAlN}) P_{t} / P_{c} / P_{c}
\end{aligned}
$$

This choice of combination gives the possibility to treat the extreme levels of the residual stresses in all multilayer coatings. Other combinations on these films and related analyses may be achieved in future experiments. However, the associated results would be expected in the range of observations detailed hereafter. Our primary focus was only restricted to the analyses of extreme combinations.

\subsection{Characterization Methods}

The morphological and physicochemical properties as well as the thin film coating thicknesses have been determined by Scanning Electron Microscopy (SEM) and Transmission Electron Microscopy (TEM) observations, followed by energydispersive x-ray spectroscopy (JEOL JSM-5900 LV) microanalyses in the surface. A Siemens D500 x-ray diffractometer $(40 \mathrm{kV}, 30 \mathrm{~mA})$ has been used to determine the crystal structure with $\theta-2 \theta$ scanning mode, using $\operatorname{CoK} \alpha$ as the radiation source $(\lambda=0.78 \mathrm{~nm})$. The scanning has been performed at an angle ranging from 20 to $120^{\circ}$, for which the angle size and the score time at each step were set to $0.05^{\circ}$ and $10 \mathrm{~s}$, respectively. The determination of the surface composition is carried out by EDS microanalysis. The cross-sectional microstructure was observed by HR-TEM (HF3300 I2TEM). The nanoindentation experi- ments (nanoindenter type: CSM 2-107) were performed with a Berkovich diamond indenter, and a load ranging from 0.1 to $700 \mathrm{mN}$ (load resolution of $50 \mathrm{nN}$ and depth resolution lower than $0.01 \mathrm{~nm}$ ). The hardness measurements were performed into five points on the same sample surface. Therefore, twentyfive indentation tests by sample were developed in this range of loads. Several indentation tests have been made for all coatings, and the average value was calculated for more accurate results with the associated standard deviation. The load was held at $70 \%$ of the highest load for $60 \mathrm{~s}$ to correct the thermal drift (Ref 26). The tip geometry and instrument compliance were calibrated before any test. The theoretical model developed by Rahmoun (Ref 27) was applied to determine the hardness of the films. Surface topography and morphology of the layer were observed by AFM (Digital Instruments-Santa BarbaraMultiMode SPM Model NanoScope IIIa-CA). AFM was operated in tapping mode imaging by acquiring three fields with a scan size of $3 \times 3 \mu^{2}$. The coating composition was characterized by XPS using ESCA 3000 (VG Microtech), equipped with a monochromatic aluminum system $\mathrm{K} \alpha$ x-ray beam (energy $=1486.5 \mathrm{eV}$ and $150 \mathrm{~W})$.

In the case of the study of residual stresses, only the internal stress, $\sigma_{t}$ was considered and evaluated (thermal stress and external stresses were not considered as their values are lower that internal stresses contribution) (Ref 28-34). The Stoney formula based on the curvature measurement of samples is generally used to determine the residual stress value (Ref 33):

$\sigma_{i}=\frac{1}{6} \frac{E_{s}}{1-v_{s}} \frac{t_{s}^{2}}{t_{f}}\left(\frac{1}{R}-\frac{1}{R_{0}}\right)$

where $E_{s}$ and $v_{s}$ are the Young's modulus $(130 \mathrm{GPa})$ and Poisson's ratio (0.28) of the silicon (100) (Ref 28), $t_{s}$ and $t_{f}$ are the substrate and the film thicknesses, respectively. $R_{0}$ and $R$ are the substrate curvature radius before and after coating.

However, the application of the Stoney formula requires assuming several hypotheses (Ref 34). Firstly, the substrate and coating thicknesses are smaller than their lateral dimensions. Moreover, the difference between the two thicknesses is high and the geometry of the sample is considered as homogeneous

\begin{tabular}{|c|c|c|c|c|c|}
\hline \multirow[b]{2}{*}{ Coatings } & \multicolumn{2}{|c|}{ Target bias voltage, $\mathrm{V}$} & \multirow[b]{2}{*}{ Deposition time, min } & \multicolumn{2}{|c|}{$\begin{array}{c}\% \text { of gas in the } \\
\text { plasma }\end{array}$} \\
\hline & Al & $\mathbf{C r}$ & & Ar & $\mathbf{N}_{2}$ \\
\hline \multicolumn{6}{|l|}{ Monolayer } \\
\hline $\mathrm{Cr}$ & 0 & & 3 to 60 & 100 & 0 \\
\hline $\mathrm{CrN}$ & 0 & -900 & 7 to 60 & 80 & 20 \\
\hline CrAIN & -300 & & 7 to 60 & & \\
\hline \multicolumn{6}{|l|}{ Multilayer } \\
\hline $\mathrm{PVD}_{1}:(\mathrm{CrN} / \mathrm{CrAIN}) P_{t} / P_{t}$ & & & 105.5 & & \\
\hline $\mathrm{PVD}_{2}:(\mathrm{Cr} / \mathrm{CrN} / \mathrm{CrAIN}) P_{t} / P_{t} / P_{t}$ & & & 99 & & \\
\hline $\mathrm{PVD}_{3}:(\mathrm{CrN} / \mathrm{CrAIN}) P_{c} / P_{c}$ & -300 & -900 & 22.5 & 80 & 20 \\
\hline $\mathrm{PVD}_{4}:(\mathrm{Cr} / \mathrm{CrN} / \mathrm{CrAIN}) P_{c} / P_{c} / P_{c}$ & & & 29.5 & & \\
\hline $\mathrm{PVD}_{5}:(\mathrm{CrN} / \mathrm{CrAIN}) P_{t} / P_{c}$ & & & 28 & & \\
\hline $\mathrm{PVD}_{6}:(\mathrm{Cr} / \mathrm{CrN} / \mathrm{CrAIN}) P_{t} / P_{c} / P_{c}$ & & & 25.5 & & \\
\hline
\end{tabular}
and isotropic. In addition, the stress and the radius of curvature are also homogeneous on the entire samples surface. The radii of curvature were determined from the Newton rings measurements (Fig. 1) (Ref 35). The optical apparatus is composed of a

Table 1 Time and deposition conditions of the thin film systems 
sodium vapor source $(\lambda=589.3 \mathrm{~nm})$, a semi-transparent lens, a sample holder as well as focusing and projection lenses. The following relation links the experimental observations developed through this optical device:

$d^{2}=4 R \lambda m$

where $d$ is the diameter of the ring, $m$ is the ring number and $R$ is the curvature radius of the sample. After the analysis of the interference rings, the linear relation (Eq 2) is used to determine this curvature radius. Indeed, the calculation of the slope, $\alpha$, of the relation between square diameter and associated ring number after experimental observations allows us to estimate this parameter, which is given by the simple relation:

$R=\frac{\alpha}{4 \lambda}$

The radius value is then replaced in the STONEY equation (Eq 1). A tensile stress is obtained when the curvature of the sample is concave, while a compressive stress is considered when this curvature radius is convex. The positive sign is used regarding the international convention for tensile stress. In the opposite case (convex shape), a compressive film stress is obtained corresponding to a negative value. This approach has been developed on the three monolayer coatings $(\mathrm{Cr}, \mathrm{CrN}$ and $\mathrm{CrAlN}$ ) developed on the silicon substrate for various deposition times.

Reciprocating wear tests have been performed using a micro-tribometer (Oscillating TRIBO-tester, TRIBO technique), equipped with an alumina ball $\left(\mathrm{Al}_{2} \mathrm{O}_{3}\right)$ with a diameter of $10 \mathrm{~mm}$ and a roughness $R_{a}$ of about $0.52 \mu \mathrm{m}$. The tests have been conducted under different normal loads $(3,5,8,10$, and $12 \mathrm{~N}$ ) during $15 \mathrm{~min}$, reciprocated at a frequency of about $2 \mathrm{~Hz}$ and with amplitude of $5 \mathrm{~mm}$. The tests have been performed at ambient atmosphere (temperature of $22{ }^{\circ} \mathrm{C}$ with $31 \%$ humidity) without lubrication. 3D optical profilometer (VEECO-OPTICAL 3030) was used to determine the wear track morphology.

\section{Results and Discussions}

\subsection{Monolayer Coatings Study}

$\mathrm{Cr}, \mathrm{CrN}$ and $\mathrm{CrAlN}$ monolayer coatings were synthesized by magnetron sputtering (Table 1). The limiting factors for the application of these coatings for protecting cutting tools are their lack of adhesion and wear resistance. Consequently, as mentioned previously, it is proposed to superimpose these coatings with different level of residual stresses in order to develop a multilayer coating with enhanced mechanical and tribological properties.

3.1.1 Mechanical Properties. The nanoindentation measurements permit to determine the average hardness in monolayer coating as shown in Fig. 2(a) for a 1- $\mu$ m-thick CrAlN layer. The Young modulus of coatings could also be measured with this approach if required. The hardness values of each load cycle are plotted as a function of the penetration depth as shown in Fig. 2(b) for the CrAlN coatings. This nanohardness-depth profile can be explained by the presence of the hard film and its intrinsic properties leading to large value in the initial depth domain. The mean values of hardness and residual stresses were determined for all monolayers with different thicknesses based on the Martens hardness analysis method as proposed by Rahmoun et al. (Ref 27). Figure 3 shows that the residual stress deviates directly from the sample to reach a maximum $\left(P_{c}\right)$ and then stabilizes $\left(P_{t}\right)$ over the rest of the film thicknesses for longer deposition times, meaning that compressive stress is present and stable. In particular, several authors studied the thickness effect on the residual stresses and have shown that the residual stresses are inhomogeneous

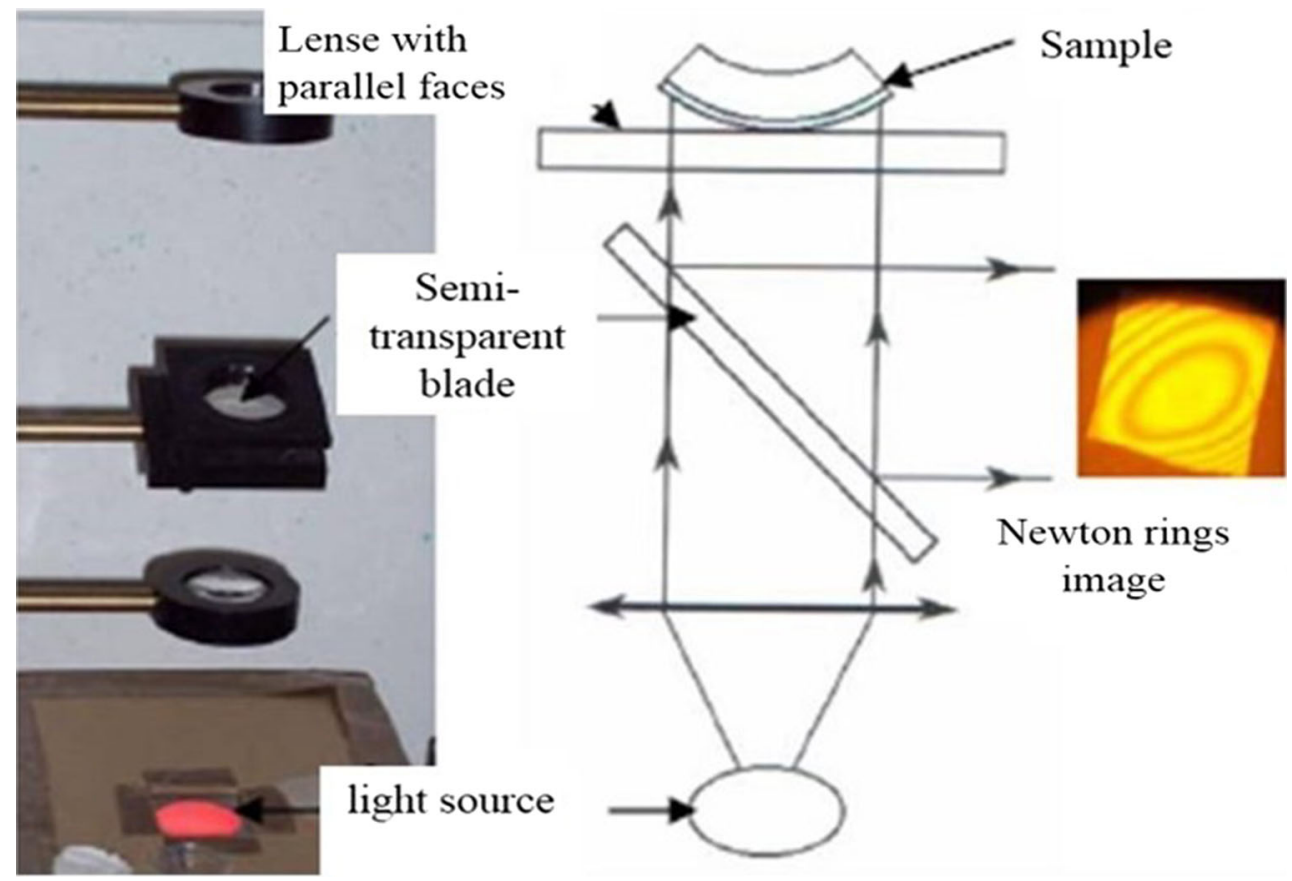

Fig. 1 Newton rings experimental equipment 

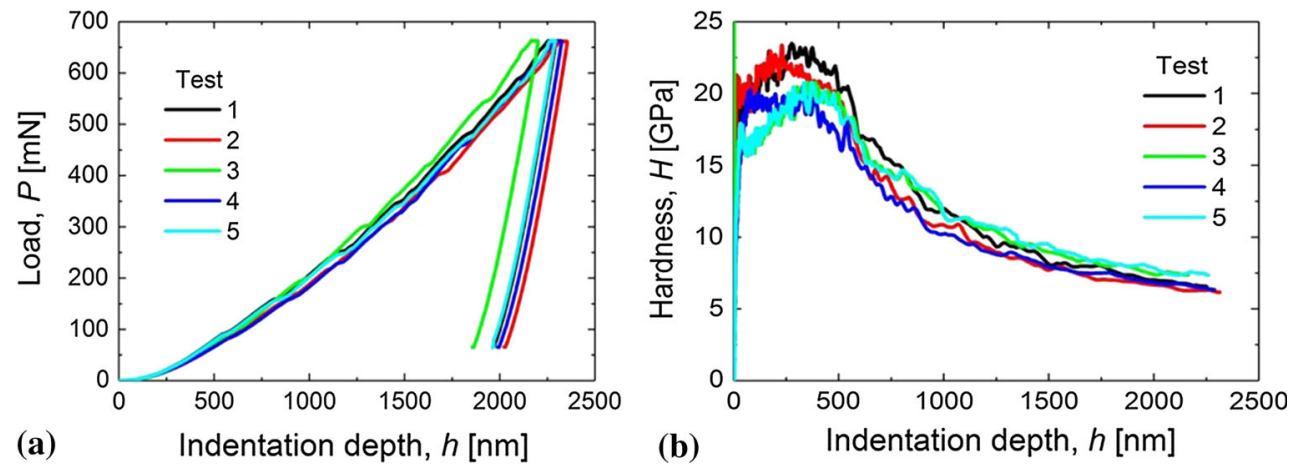

Fig. 2 Characterization of the CrAlN monolayers (thickness of $1 \mu \mathrm{m}$ ) through five nanoindentation instrumented tests. (a) Loading-unloading curves with the load evolution, $\mathrm{P}$, as a function of the indenter displacement, $\mathrm{h}$, (b) Variation of current hardness, H, as a function of the indent displacement, h, measured with the indent vibration approach (Frequency $45 \mathrm{~Hz}$, Amplitude of displacement $2 \mathrm{~nm}$ )
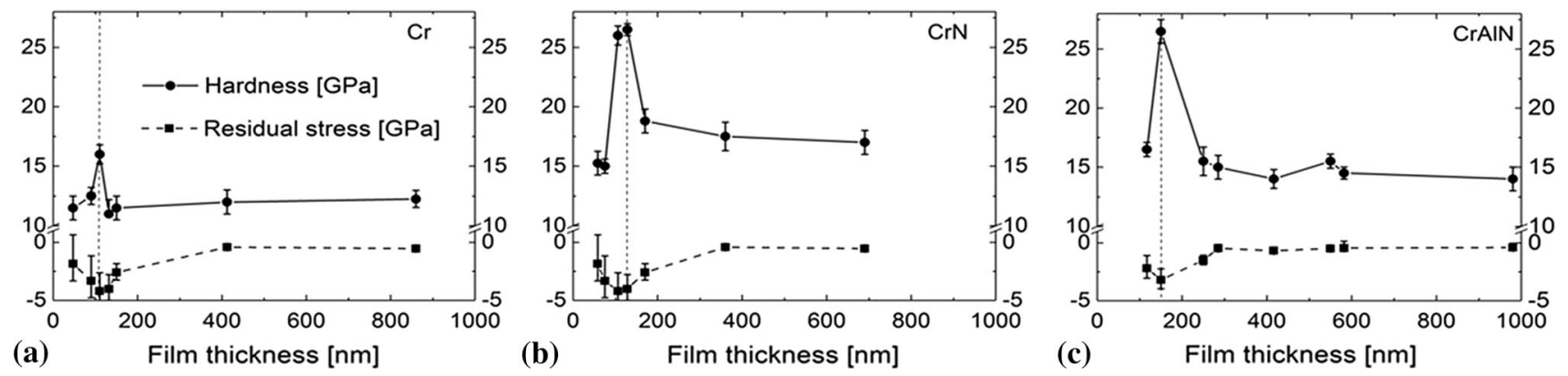

Fig. 3 Evolution of the hardness (plain lines), H, and residual stresses (dashed lines), $\sigma_{\mathrm{r}}$, as a function of the film thickness, for: (a) Cr, (b) $\mathrm{CrN}$ and (c) CrAlN layers deposited on silicon substrate. The magnitudes of compressive residual stresses (negative) are shown in the lower domain due to their negative values (compressive stresses)

depending from the layer thickness (Ref 36-38). In our study, the maximum hardness values for the $\mathrm{Cr}, \mathrm{CrN}$ and $\mathrm{CrAlN}$ layers are, respectively, 16, 28 and $26.5 \mathrm{GPa}$ (accuracy $\approx \pm 1 \mathrm{GPa}$ ) associated with the thickness values of 110 , 120 and $150 \mathrm{~nm}$. The associated residual stresses are, respectively, $-4,-5.3$ and -3.6 GPa (Fig. 3). It should also be noticed that similar evolutions are observed for residual stress and hardness as a function of the indentation depth. Different effects can explain the stress peak $\left(P_{c}\right)$ : the creation of defects, the change of crystal orientation or the densification during the layer growth (Ref 36-48). This peak generally depends on the deposition conditions and the composition of the layer itself.

3.1.2 Residual Stresses and Morphology Interaction. The AFM observations showed that in the initial stage of film deposition, the development of layer occurs unevenly in an island growth mode. Indeed, Fig. 4 shows this phenomenon as observed in the direction normal to the surface (upper view). An average island stress is smaller than the one encountered in a uniform layer thickness due to the partial stress reduction in a land's peripheral area. The stress reduction rate is commonly determined by the ratio of thickness to size of the islands. Early in the formation of the CrAlN layer, the nucleation and progressive development of many tiny islands are observed on the substrate corresponding to the initial step before coalescence mechanism (Fig. 4a). The residual stresses level is considered significantly small since these nuclei are tiny and minor. These stresses are attributed to a balance between surface stresses and interface stresses, and not only to the spontaneous generation of residual stresses in the island. As deposition time gradually increases, a progressive coalescence of the tiny nuclei is observed aiming at forming continuous islands (Fig. 4b).

\subsection{Multilayers Coatings Study}

The superposition of monolayers with different levels of residual stresses leads to the development of multilayer coatings (Table 2). The analysis and comparative study between the various multilayer coatings systems $\left(\mathrm{PVD}_{1}\right.$ to $\mathrm{PVD}_{6}$ ) are based on the nature of layers, the total thickness of the film and the residual stress levels in the monolayers.

3.2.1 Composition and Structure. The $\mathrm{Cr}, \mathrm{CrN}$ and CrAlN coatings with different thicknesses were successfully deposited on a silicon substrate in order to control and optimize the residual stresses. Through the development of binary and ternary layers under optimal conditions, we developed $\mathrm{Cr} / \mathrm{CrN} /$ CrAlN and CrN/CrAlN multilayer coatings Cr-based (Fig. 5) on AISI 4140 steel substrate. The thickness, roughness and chemical composition of the films are detailed in Table 2. Even if the SEM observations show a dense multilayer coating, they do not provide sufficient accurate information on the fine microstructure. Then, HR-TEM was used to provide additional observations. Observations (Fig. 6) have been done on coatings with specific thicknesses corresponding to minimal residual stresses (Fig. 3) (i.e., the $\mathrm{Cr}, \mathrm{CrN}$ and $\mathrm{CrAlN}$ monolayers thicknesses with, respectively, thicknesses of 10,50 and $65 \mathrm{~nm})$. The $\mathrm{PVD}_{2}$ coating was developed with $P_{t}$ condition 


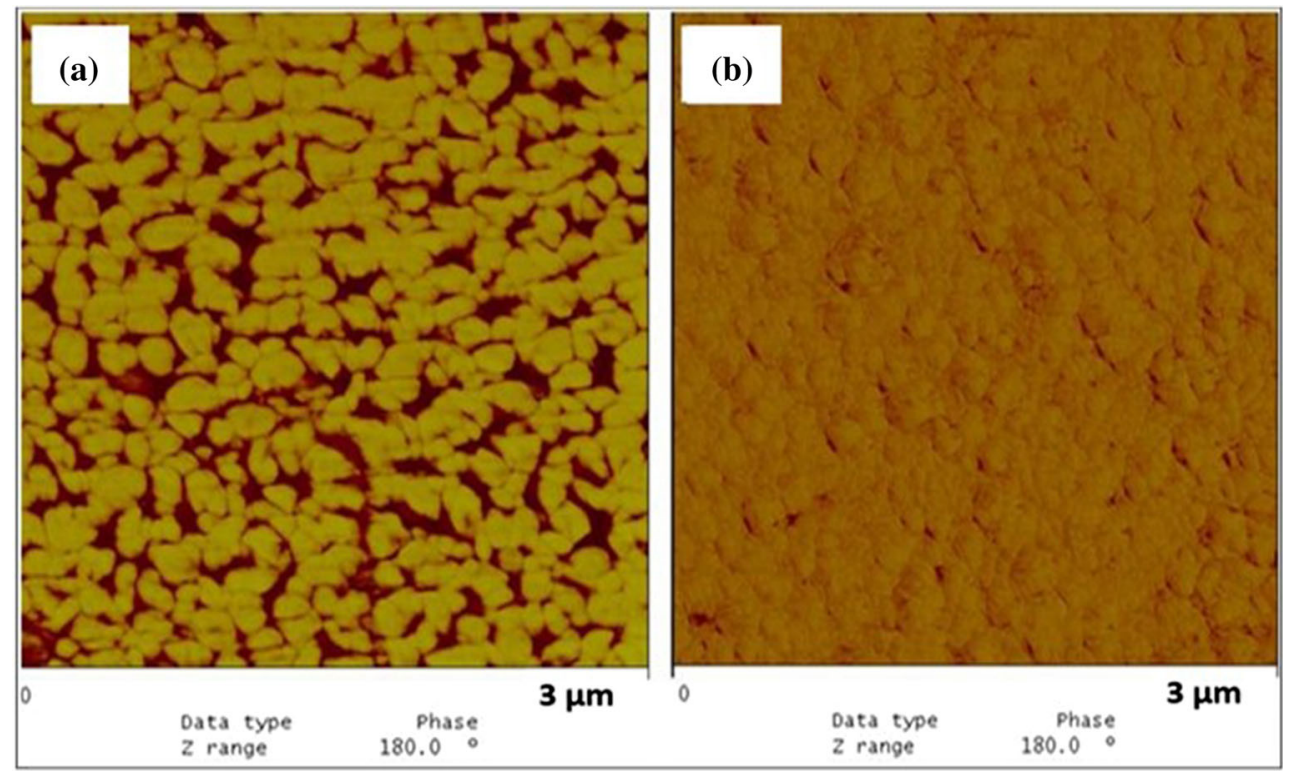

Fig. 4 AFM images of CrAlN film on a silicon substrate for an average film thickness of (a) $\sim 5 \mathrm{~nm}$ and (b) $\sim 700 \mathrm{~nm}$. Direction of observations is perpendicular to the surface of the sample and similar to the growth direction of coating. Observations are reported on the AFM analysis domain of $3 \times 3 \mu \mathrm{m}^{2}$

Table 2 Roughness, total thickness and composition of the thin film systems

\begin{tabular}{|c|c|c|c|c|c|}
\hline Coatings & $\mathrm{N}$, at. $\%$ & Al, at. $\%$ & Cr, at.\% & Total thickness $t, \mathrm{~nm}( \pm 10 \mathrm{~nm})$ & Arithmetic roughness, $\boldsymbol{R}_{\mathrm{a}}, \mathbf{m m}( \pm \mathbf{0 . 0 1} \mathrm{nm})$ \\
\hline \multicolumn{6}{|c|}{ Monolayers } \\
\hline $\mathrm{Cr}$ & 0 & 0 & 98 & 47 to 860 & 0.1 to 0.12 \\
\hline $\mathrm{CrN}$ & 28.5 & 0 & 71 & 58 to 690 & 0.1 to 0.12 \\
\hline CrAIN & 29 & 3.5 & 67 & 50 to 980 & 0.1 to 0.12 \\
\hline \multicolumn{6}{|c|}{ Multilayers } \\
\hline $\mathrm{PVD}_{1}$ & 52 & 5 & 41.3 & 1500 & 0.11 to 0.13 \\
\hline $\mathrm{PVD}_{2}$ & 51.8 & 4.2 & 42.9 & 1500 & 0.1 to 0.12 \\
\hline $\mathrm{PVD}_{3}$ & 49.7 & 4.9 & 43.6 & 256 & 0.11 to 0.12 \\
\hline $\mathrm{PVD}_{4}$ & 50.1 & 4.2 & 44.5 & 360 & 0.09 to 0.11 \\
\hline $\mathrm{PVD}_{5}$ & 50.8 & 4 & 43.1 & 300 & 0.1 to 0.12 \\
\hline $\mathrm{PVD}_{6}$ & 50.5 & 4.7 & 42.5 & 300 & 0.1 to 0.11 \\
\hline
\end{tabular}

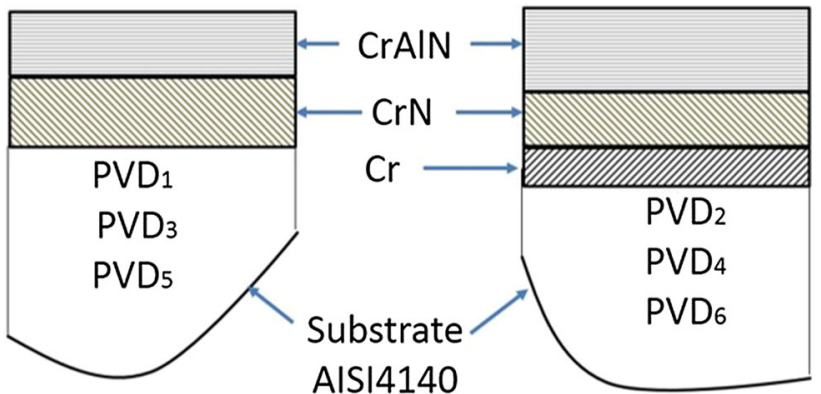

Fig. 5 Schemes of the $\mathrm{Cr} / \mathrm{CrN} / \mathrm{CrAlN}$ and $\mathrm{CrN} / \mathrm{CrAlN}$ multilayers coatings on AISI4140 steel substrate

with higher monolayer thicknesses. We chose to observe very thin layers by TEM to facilitate the observation and to reduce the sample preparation duration. The multilayer is largely composed of regular crystals of a few nanometers size. This can be considered as quite small crystals. From the substrate to the multi-layered top surface, a regular microstructural arrangement is observed. The HR-TEM observation shows a $\mathrm{Cr}$ thin layer with a thickness of $10 \mathrm{~nm}$ parallel to the coating/substrate interface. This layer is created during the first growth stage. It is followed by a succession of $\mathrm{CrN}$ nanolayers of 3 to $3.5 \mathrm{~nm}$ thicknesses. The thickness of the whole $\mathrm{CrN}$ layer is about $50 \mathrm{~nm}$, followed by the CrAlN top surface layer with a thickness of approximately $65 \mathrm{~nm}$. The thickness of $\mathrm{Cr}, \mathrm{CrN}$ and CrAIN layers was controlled by the deposition time. The superficial layer is possibly crystallized. This type of arrangement is probably related to the effect of residual stresses in the monolayers. The variation of the residual stresses as a function of the film thickness is not homogeneous in each monolayer, which can generate an internal interaction in the multilayer coatings. It should be mentioned that this interaction contributes to several phenomena as the microstructural arrangement or the adhesion of the coatings. In addition, the layer subjected to residual compressive stresses may undergo 
delamination or some other damages. One can note that the initial delamination process occurs by crack extension along a plan parallel to the deposition surface. This phenomenon generally occurs at the film/substrate interface and is described in our case by the delamination of the chromium underlayer deposited on the substrate (Fig. 6a). Subsequently, an increase in the coating thickness leads to the disappearance of the ordered superimposed monolayers. Indeed the formation of a mixed phase (amorphous and crystalline) is observed with spheroidal grains (20 nm of diameter) in the magnification of the upper coating domain (Fig. 6b). The behavior is probably related to the relaxation of residual stresses. This phenomenon is also due to the substitution of $\mathrm{Cr}$ atoms with the smaller $\mathrm{Al}$ ones, which results in the contraction of the $\mathrm{CrN}$ lattice. In addition, this phenomenon can be related to phase separation of the hexagonal aluminum nitride h-AlN from the supersaturated solid solution of CrAlN. Although the maximum solubility of AlN in cubic CrN is around 77 mol.\% (Ref 48, 49), the supersaturated CrAIN phase is thermodynamically metastable and its stability strongly depends on the deposition conditions. This nanocrystallized phase is attributed to $\mathrm{CrN}$ (111) phase while $\mathrm{Al}$ is implanted in the amorphous phase. Therefore, small localized and dispersed nanocrystals can be identified in the rest of the surface after cross-sectional observation. It is reasonable to consider that this morphological evolution in the multilayer coatings is particularly related to those internal stresses.

Concerning the structure analysis by XRD, we limited our study to $\mathrm{PVD}_{1}$ and $\mathrm{PVD}_{2}$ patterns due to the thinness of the other films. These thin films are elaborated with moderate residual stresses $\left(\sigma_{i}<0.4 \mathrm{GPa}\right)$. Figure 7 shows the synthesized XRD patterns of $\mathrm{PVD}_{1}$ and $\mathrm{PVD}_{2}$ nanoscale multilayers $1500 \mathrm{~nm}$ thick. Both multilayers were well crystallized in a cubic structure. For $\mathrm{PVD}_{1}$ film, the main diffraction peaks (111) and (220) are detected at $43.7^{\circ}$ and $76.7^{\circ}$, respectively. This can be related to the $\mathrm{CrN}$ cubic phase structure (JCPS $\mathrm{N}^{\circ} 11-0065$ ). The analysis of the $\mathrm{PVD}_{2}$ thin film shows that the $\mathrm{CrN}$ (111) diffraction peak has completely disappeared, while the $\mathrm{CrN}$ (311) diffraction peak appeared predominantly at $91^{\circ}$, com- pared to the lower (220) crystalline orientation. This result can be explained by the higher growth speed of (311) plans compared to (111) plans, or by the preferential sputtering effect of nitrogen atoms on (111) plans (Ref 44).

Qualitative XPS profiles of $\mathrm{PVD}_{2}$ multilayers (deposited on silicon) elementary composition were established after three argon etching durations $\left(t_{1}=600 \mathrm{~s}, t_{2}=1500 \mathrm{~s}\right.$ and $\left.t_{3}=2520 \mathrm{~s}\right)$. The interlayers/underlayer and underlayer/substrate interfaces are not greatly sharp (Fig. 8a). Moreover, Fig. 8(b) shows high-resolution XPS core-level spectra of $\mathrm{Cr}$ metal formed by two peaks centered at $574.81\left(\mathrm{Cr}_{2 \mathrm{p} \mathrm{3/2}}\right)$ and $584 \mathrm{eV}\left(\mathrm{Cr}_{2 \mathrm{p}}\right.$ 1/2). The $\mathrm{N}_{1 \mathrm{~s}}$ spectrum (Fig. 8c) reveals the presence of a nitrogen characteristic peak in cubic chromium nitride centered at $396.46 \mathrm{eV}$. Similarly, the $\mathrm{Al}_{2 \mathrm{p}}$ spectrum (Fig. 8d) shows a main peak with a binding energy of $74.3 \mathrm{eV}$ corresponding to AIN (Ref 44). Furthermore, the $\mathrm{Cr}_{3 \mathrm{~s}}$ with $\mathrm{Al}_{2 \mathrm{p}}$ XPS peaks are very similar because the energy level corresponding to these two elements are close to each other. To complete this study, we measured the width at half-height on the same profile spaces of all elements of the $\mathrm{PVD}_{1}$ thin film. It should be noticed that the Cr peak becomes more intense when

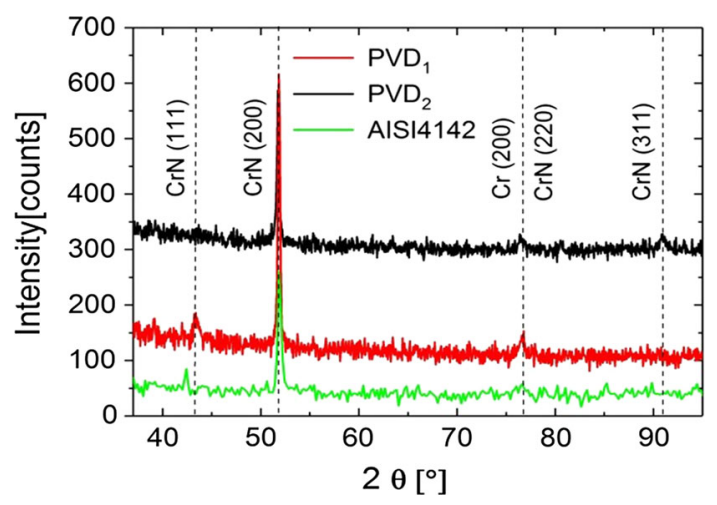

Fig. 7 XRD patterns of the $\mathrm{PVD}_{1}, \mathrm{PVD}_{2}$ multilayers and of the AISI4140 steel substrate

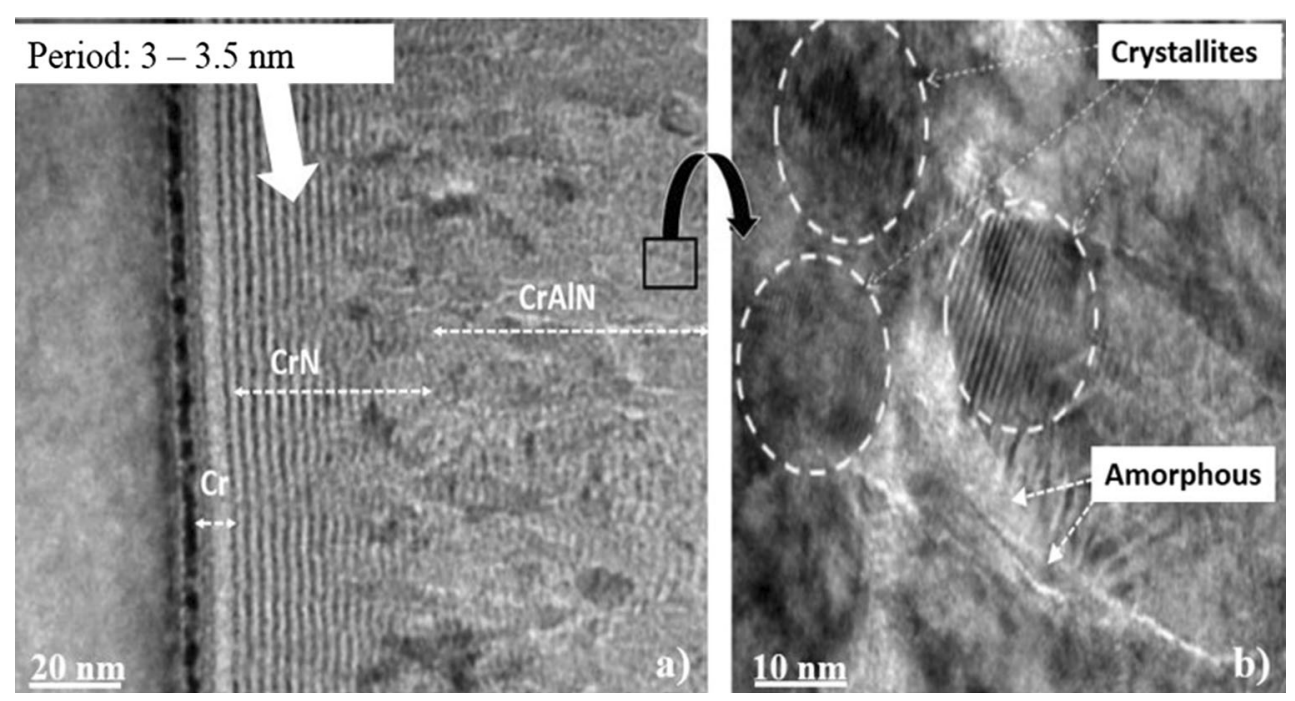

Fig. 6 HR-TEM cross-sectional images of a $\mathrm{Cr} / \mathrm{CrN} / \mathrm{CrAlN}$ multilayer (respective thicknesses: $\mathrm{Cr}=10 \mathrm{~nm}, \mathrm{CrN}=50 \mathrm{~nm}$ and $\mathrm{CrAlN}=65 \mathrm{~nm}$ ) (a) Nanolayers at the substrate/film interface (thickness period of 3 to $3.5 \mathrm{~nm}$ ), and columnar grains, (b) Dispersion of the crystallites in a partially amorphous structure 

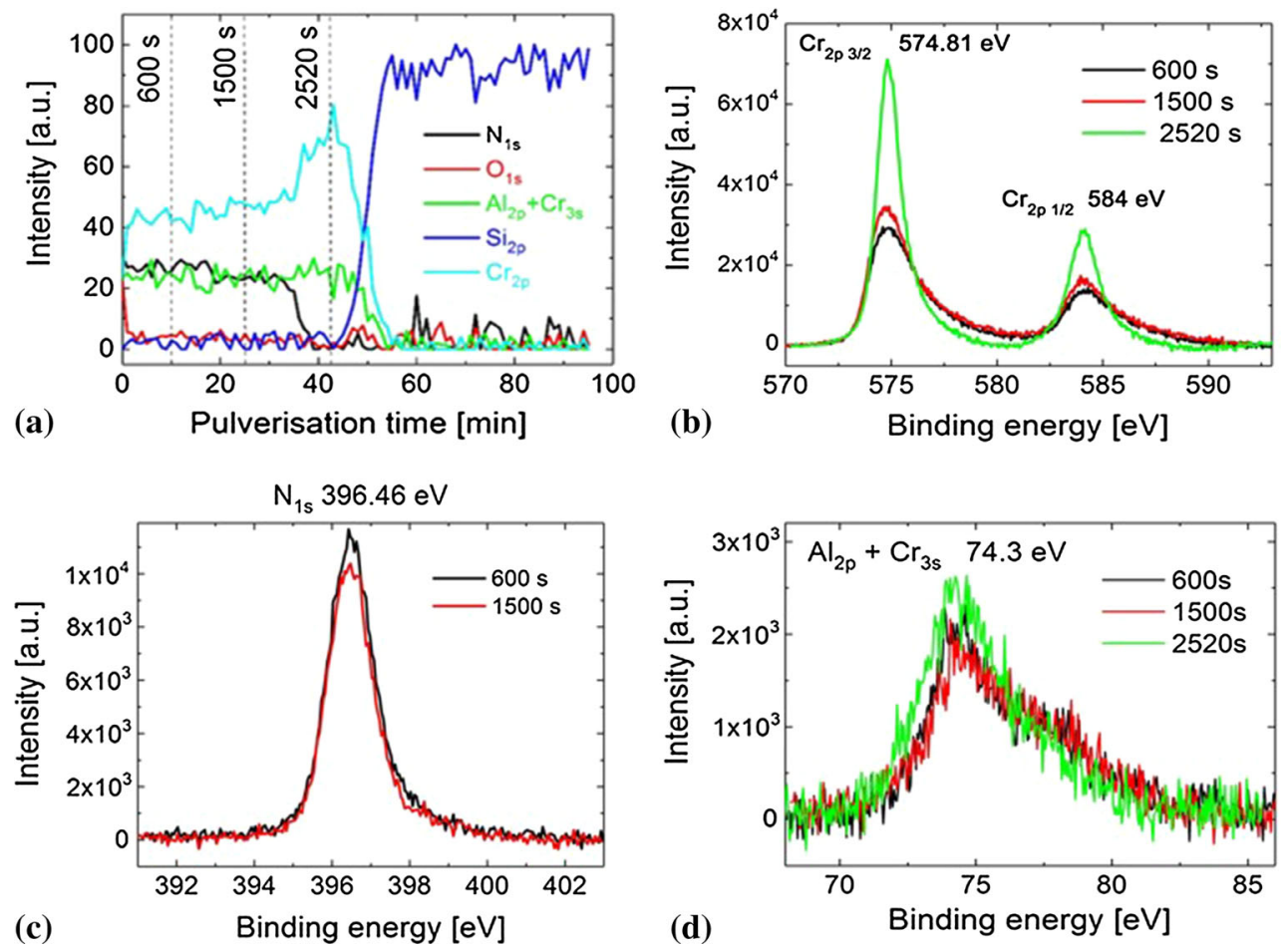

Fig. 8 (a) XPS core-level spectra of $\mathrm{Cr} / \mathrm{CrN} / \mathrm{CrAlN} / \mathrm{Si}$ as a function of the etching duration, and: (b) $\mathrm{Cr}_{2 \mathrm{p}},(\mathrm{c}) \mathrm{N}_{1 \mathrm{~s}}$ and (d) $\mathrm{Al}_{2 \mathrm{p}}+\mathrm{Cr}_{3 \mathrm{~s}}$ spectra

the etching duration is maximum $\left(t_{3}\right)$, and its width at halfheight increases from $1.3 \mathrm{eV}$ for time $t_{1}$ to $2.6 \mathrm{eV}$ for time $t_{3}$ (Fig. 8b). This transition is explained by the presence of pure metallic chromium at $t_{1}$. Moreover, for time $t_{2}$ and $t_{3}$, the width at half-height is 2.5 and $2.6 \mathrm{eV}$, respectively, which justifies the presence of a unique phase in both $\mathrm{CrN}$ and $\mathrm{CrAlN}$ layers, probably cubic chromium nitride. A measure of the width at half-height (with a binding energy of $4 \mathrm{eV}$ ) was also performed on the $\mathrm{Al}_{2 \mathrm{p}}$ and $\mathrm{Cr}_{3 \mathrm{~s}}$ peaks (Fig. 8d). The obtained results are identical and may be the consequence of the presence of AIN. These results correlate with the compositional analyses obtained by EDS and XRD. The XRD pattern of this coating shows the presence of a low crystallized film with broad peaks related to the contribution of $\mathrm{Cr}_{2} \mathrm{~N}, \mathrm{CrN}$ and $\mathrm{AlN}$. As a result, we can also consider that the $\mathrm{Cr}$ present in this film is bonded to nitrogen and forms $\mathrm{Cr}_{2} \mathrm{~N}$. It is therefore possible that the CrAlN top layer is multiphased and consists of $\mathrm{Cr}_{2} \mathrm{~N}, \mathrm{CrN}$ and $\mathrm{AlN}$.

3.2.2 Residual Stresses. Almost any type of thin hard coating contains residual stresses resulting from the manufacturing process. They can be a result of growth mechanisms, or fast cooling from a high deposition temperature if there is a substantial difference in thermal expansion between the coating and substrate materials. The coatings growth with temperature gradients at the substrate surface or interfaces between coatings allows superimposing nanoscale gradients in the composition structure (Ref 44, 45). These phenomena accompanied with a substrate bias modulation induced intermixing or relaxation of residual stresses at the interface of the intermediate layers, which may also result in an enhancement of physical and mechanical properties of the coatings (Ref 44-46). Comparing Fig. 3 and 9, the results indicate that residual stresses in multilayers are lower than those measured in single-layer components. According to the experimental measurements, it is clear that the stress values obtained on the multilayers are linked to the level of those previously determined in the monolayers. Indeed, during the superposition of different films, an interaction occurs between the monolayers reducing the intensity of the overall residual stress in the total coating. The maximum value found is measured in the $\mathrm{PVD}_{4}$ multilayer, where the constitutive layers are developed with high residual stress, reflecting this dependency. On the other hand, the $\mathrm{Cr}$ bonding or transition layer plays a main role on the stress intensity. Indeed, the level of residual stresses in the $\mathrm{PVD}_{4}$ coating with a chromium underlayer $(-1.2 \mathrm{GPa})$ is higher than in the $\mathrm{PVD}_{3}$ coating without a chromium underlayer $(-0.7$ $\mathrm{GPa}$ ). This underlayer provides a good adhesion of the entire film with the substrate. The investigation of the internal stresses at the substrate/coating interface is of interest as the stresses imposed on the first layers of atoms of the coating greatly affect the growth of the developed layers. The residual stresses in the films are created by both extrinsic and intrinsic residual stresses. This latter is caused by a mismatch of thermal contraction between coatings. Besides, this reduction of residual stresses in multilayers compared to those in the constitutive monolayers is mainly due to the interface between these layers. The interlayers and the transition seem to be effective in reducing residual stress effect during the film growth. The limit of thickness of the coating showing a maximum stress is observed in many previous works (Ref 9, 44) and is also confirmed by the present results.

3.2.3 Tribological Behavior. The optimization of the tribological properties of nanostructured coatings is an important research program, given their potential application in the field of machining or stamping. The residual stresses seem to be the main characteristics of the deposit coatings to be optimized in order to improve their wear resistance. The analyses detailed 


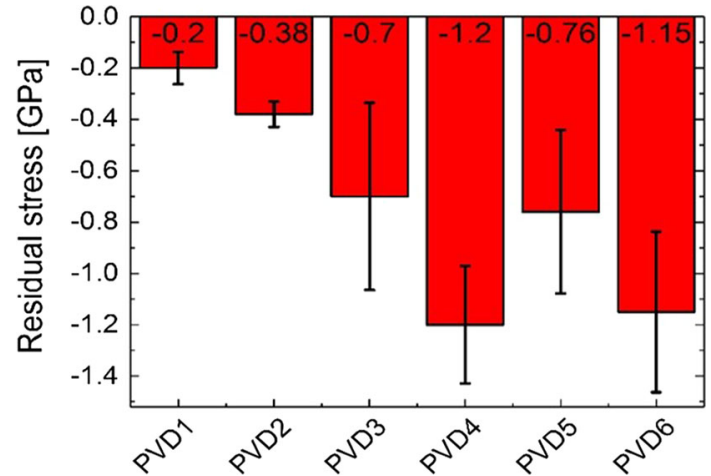

Fig. 9 Residual stresses of the PVD multilayer coatings with the uncertainties domains

hereafter are mainly dedicated to the characterization of friction properties and wear mechanisms in multilayer coatings depending from their residual stress levels related to the deposit conditions.

3.2.3.1 a- Friction Coefficient. The $\mathrm{Cr} / \mathrm{CrN} / \mathrm{CrAlN}$ and $\mathrm{CrN} / \mathrm{CrAlN}$ multilayer systems are formed by monolayers whose residual stresses levels are identical ('plate' $\left(P_{t}\right)$ for $\mathrm{PVD}_{1}$ and $\mathrm{PVD}_{2}$ or 'peak' $\left(P_{c}\right)$ for $\mathrm{PVD}_{3}$ and $\left.\mathrm{PVD}_{4}\right)$ or combined ('plate' and 'peak' for the $\mathrm{PVD}_{5}$ and $\mathrm{PVD}_{6}$ systems). It should also be pointed out that the total thickness of each couples of coatings (i.e., $\mathrm{PVD}_{1} / \mathrm{PVD}_{2} ; \mathrm{PVD}_{3} / \mathrm{PVD}_{4}$ and $\mathrm{PVD}_{5} /$ $\left.\mathrm{PVD}_{6}\right)$ is of the same order of magnitude or even identical (Table 2). This methodology gives the opportunity to study properties of multilayer coatings developed with same phases but different level of residual stress leading to various intrinsic properties. The tribological properties of the as-deposited nanocomposite films were determined by reciprocating wear tests against an $\mathrm{Al}_{2} \mathrm{O}_{3}$ alumina ball under dry wear conditions. Figure 10 shows the evolution of the instantaneous friction coefficient (COF) as a function of sliding distance for the multilayers against the alumina ball. Each multilayer shows typical running-in behavior corresponding to an initial transient stage followed by an increase in the COF until a steady state. The initial transient stage corresponds to contact between the highest asperities of the ball and the coating surface. Vibrations and noise are also present in the evolutions reported in Fig. 10.

Against alumina, the COF of $\mathrm{PVD}_{1}$ is 0.36 at the beginning of the test in a short running-in period. An increase to 0.65 (Fig. 10a) of the COF is observed afterward. The wear becomes more severe leading to coating failure and to the creation of debris which participate to the wear kinetics. Moreover, $\mathrm{PVD}_{2}$ has an initial COF value of 0.28. After a friction distance of about $6 \mathrm{~m}, \mathrm{PVD}_{1}$ and $\mathrm{PVD}_{2}$ have the same COF value $(\sim 0.57)$. The shift in the transition period between the two coatings explains that $\mathrm{PVD}_{2}$ has a better tribological behavior compared to $\mathrm{PVD}_{1}$. The $\mathrm{PVD}_{3}$ coating presents a short steady state period of constant COF of 0.6 . The COF of $\mathrm{PVD}_{4}$ starts at 0.22 and increases slowly to around 0.5 . A small change in the friction behavior corresponds to the breakdown of the two coatings after $8 \mathrm{~m}$, and the COF becomes similar, as shown in Fig. 10(b). As a result, the superposition of the layers with maximum residual stresses $\left(\mathrm{PVD}_{3}\right.$ and $\left.\mathrm{PVD}_{4}\right)$ does not improve the tribological behavior. The COF shows similar behavior with the $\mathrm{PVD}_{5}$ coating (Fig. 10c). At the very beginning of the tribological test, a low value of COF property is observed $(0.25)$, but a higher value is quickly reached (0.6) probably due to high wear and coating's delamination. A stable domain is observed after this transient period with a value of $\sim 0.45$. On the other hand, $\mathrm{PVD}_{6}$ also quickly reaches the high $\mathrm{COF}$ value of 0.6 before a stable domain where a COF value of 0.5 is observed. This coating contains a $\mathrm{Cr}$ bonding underlayer with 'plate' stress $\left(P_{t}\right)$ reinforcing its tribological behavior.

As mentioned previously, it is noteworthy that a Transition zone (Tz) exists for all the multilayers where COF value evolves quickly. Although the surface layer is always the same, this zone differs from one coating to another with large differences. The length of this transient domain can be estimated as follows:

$\mathrm{Tz}\left(\mathrm{PVD}_{1}\right) \sim 3 \mathrm{~m}<\mathrm{Tz}\left(\mathrm{PVD}_{2}\right) \sim 4 \mathrm{~m}$ (Fig. 10a)

$\mathrm{Tz}\left(\mathrm{PVD}_{3}\right) \sim 0.75 \mathrm{~m}<\mathrm{Tz}\left(\mathrm{PVD}_{4}\right) \sim 1.2 \mathrm{~m}$ (Fig. 10b)

$\mathrm{Tz}\left(\mathrm{PVD}_{5}\right) \sim 0.1 \mathrm{~m}<\mathrm{Tz}\left(\mathrm{PVD}_{6}\right) \sim 0.4 \mathrm{~m}$ (Fig. 10c).

This variation is probably related to superficial tribological transformation (STT). Coatings developed with a bonding underlayer $(\mathrm{Cr})$ have also a longer $\mathrm{Tz}$ domain. Moreover, this difference in $\mathrm{Tz}$ depends mainly on several factors such as the surface topography $\left(R_{a}, R_{t}\right)$, the residual stresses in the underlayer, the adhesion energy at the interface of singleconstitutive layers, as well as the adhesion of the coatings with the substrate (Ref 50). This transition zone corresponds to the original plastic deformation (effect of the friction contact). After this transition period, the coefficient of friction stabilizes at a specific sliding length for each multilayer system. The values obtained are close to 0.58 when the surface layer is produced with 'plate' stresses $\left(P_{t}\right)$ (Fig. 10a), and close to 0.5, when multilayer systems are developed with peak $\left(P_{c}\right)$ or combined $\left(P_{t} / P_{c}\right)$ residual stresses (Fig. 10b and c). Consequently, similar COF values are obtained on the six different multilayer systems. Thereby, residual stresses in the top layer of the coating $\left(\mathrm{PVD}_{3-6}\right)$ have only a slight effect on the COF parameter. However, the accumulation of the plastic deformation in turn causes a shear stress and produces a layer failure. Two consequences of the existence of the transition zone can be noticed:

(1) The exerted shear stress exceeds the adhesion stress and causes a sudden cracking at the interface and consequently the layer spalling.

(2) The shear stress is not sufficient to generate an immediate delamination of the coating. However, when combined with the stress at the substrate interface, an initiation and/or propagation of an interfacial crack occurs and grows until a critical size is reached leading to a delamination process.

Consequently, this initial crack causes the initiation of damage under the effect of compressive residual stresses in the film. The transition period is systematically longer $(\mathrm{Tz} \approx 4 \mathrm{~m}$ for $\left.\mathrm{PVD}_{2}\right)($ Fig. 10a) and more significant in the presence of higher residual stresses $\left(\sigma_{r} \approx-0.38 \mathrm{GPa}\right.$ for $\left.\mathrm{PVD}_{2}\right)$ (Fig. 9) proving their contribution to the wear resistance and their impact to delay the damage at the contact interface. De Wit (Ref 51) found in the case of TiN layers that the transition period corresponds to the formation of third body «debris » composed of amorphous rutile and nanocrystalline grains. A transformation from the amorphous to the crystalline phase is subsequently achieved, contributing to further wear. Against alumina balls, only the $\mathrm{PVD}_{2}$ coating survived to the tribological tests as shown hereafter on Fig. 13 with the negligible value of wear volume associated to the AISI4140 substrate. The best wear 

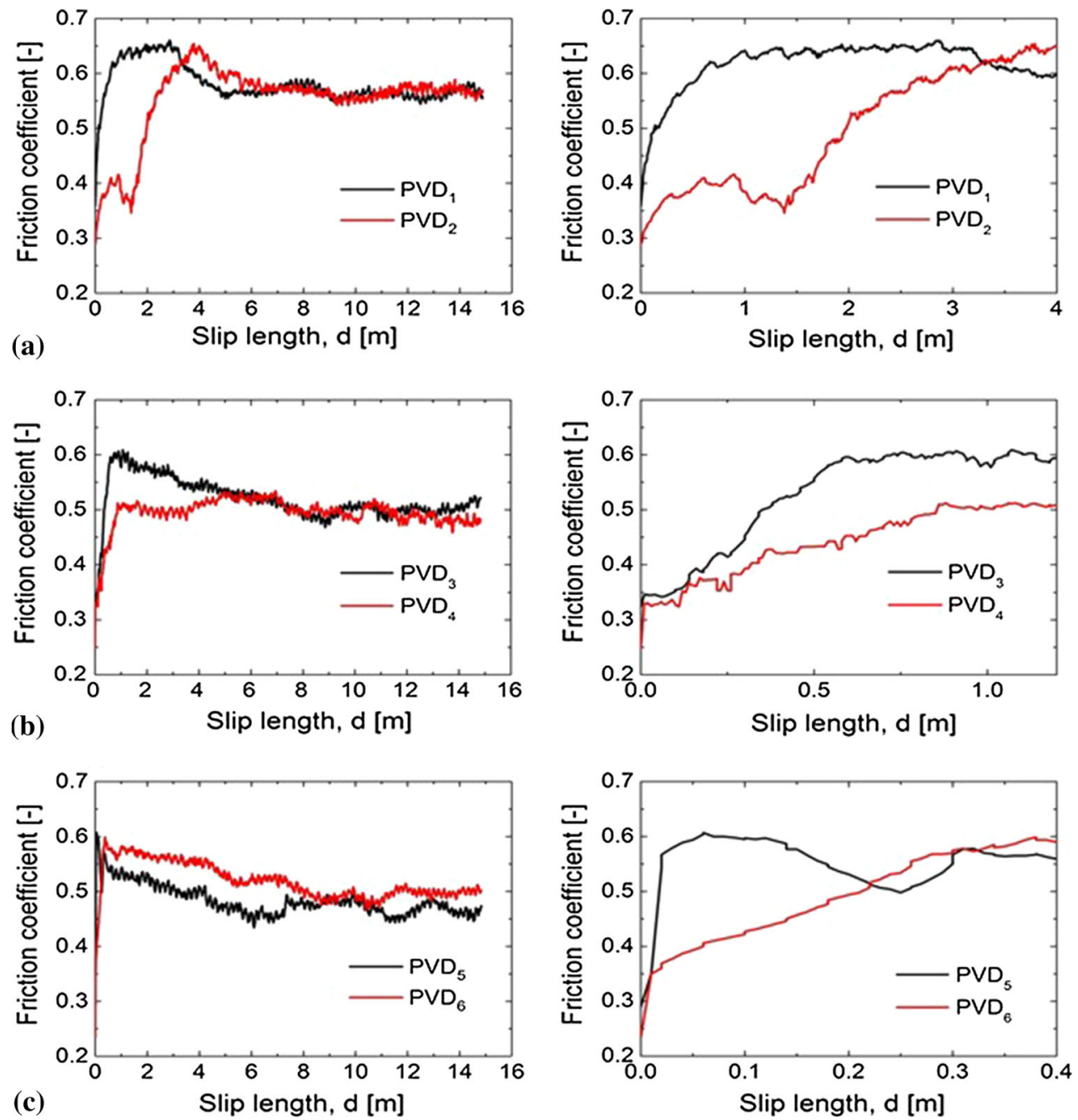

Fig. 10 Friction coefficient vs. the wear track length, $\mathrm{d}[\mathrm{m}]$, for: (a) $\mathrm{PVD}_{1}$ and $\mathrm{PVD}_{2}$, (b) $\mathrm{PVD}_{3}$ and $\mathrm{PVD}_{4},(\mathrm{c}) \mathrm{PVD}_{5}$ and $\mathrm{PVD}_{6}(\mathrm{duration}$ of friction test: $t=30 \mathrm{~min}$, Normal force applied: $F_{n}=5 \mathrm{~N}$, Speed: $v=8 \mathrm{~mm} \mathrm{~s}^{-1}$ and Amplitude of displacement: $\left.\delta= \pm 2.5 \mathrm{~mm}\right)$. Left images show the entire observation and right images provide a magnification corresponding to the transition period

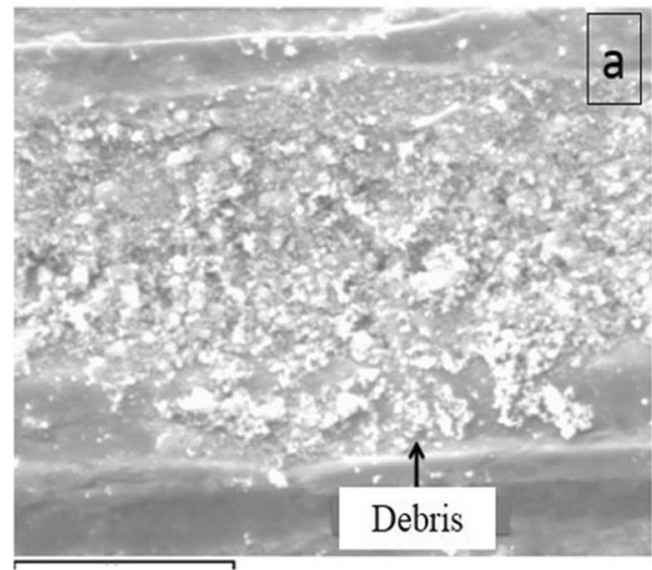

$20 \mu \mathrm{m}$

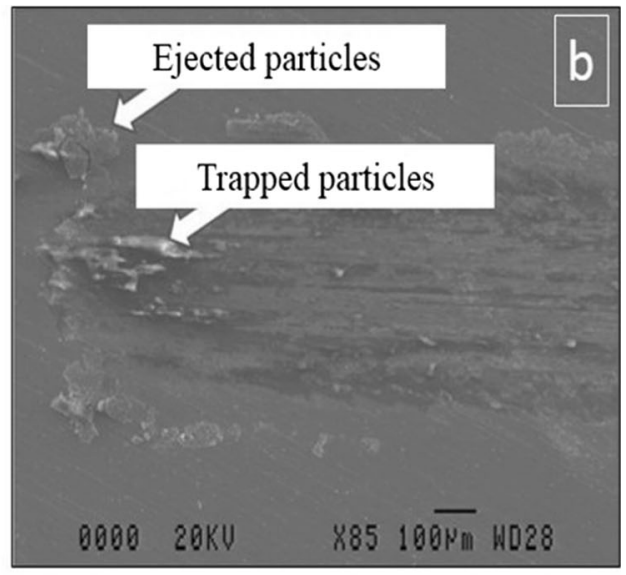

Fig. 11 SEM observations developed on the $\mathrm{PVD}_{2}$ thin film corresponding to (a) detached debris from the worn surface and, (b) wear scar morphologies (duration of the friction test: $t=15 \mathrm{~min}$, normal force applied: $F_{n}=5 \mathrm{~N}$, speed: $v=8 \mathrm{~mm} \mathrm{~s}^{-1}$ and amplitude of displacement: $\delta= \pm 2.5 \mathrm{~mm})$ 


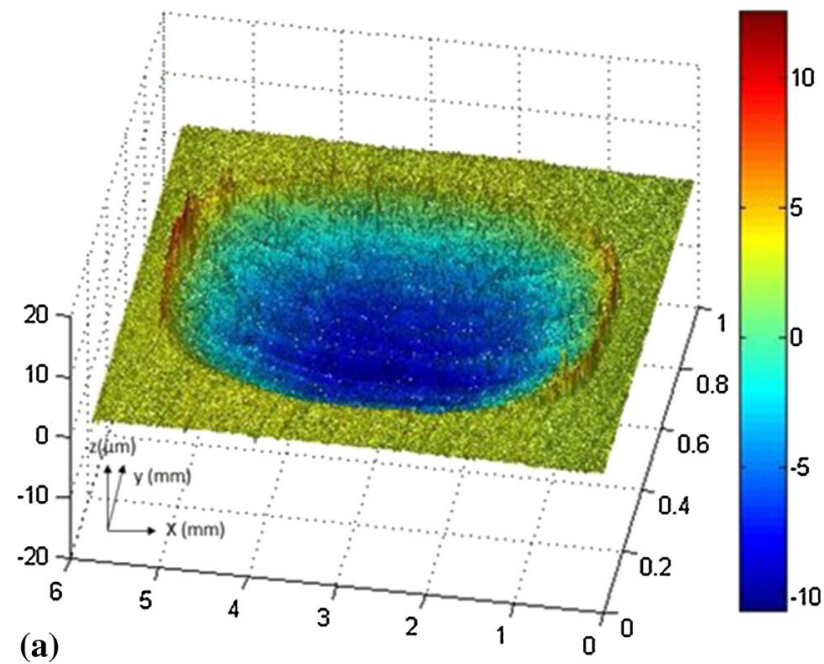

(a)

Fig. 12 Surface geometry obtained after reciprocating wear test developed on the $\mathrm{PVD}_{2}$ multilayer coating showing (a) wear tracks and (b) alumina ball $(H=16.14 \mathrm{GPa})$ with $6 \mathrm{~mm}$ in diameter. Duration of the test: $t=15 \mathrm{~min}$, normal force applied: $F n=12 \mathrm{~N}$, speed: $v=8 \mathrm{~mm} \mathrm{~s}{ }^{-1}$ and amplitude of displacement: $\delta= \pm 2.5 \mathrm{~mm}$

behavior was achieved in comparison with the other multilayer systems. Consequently, the $\mathrm{PVD}_{2}$ coating improves the friction behavior against $\mathrm{Al}_{2} \mathrm{O}_{3}$ balls.

The analysis of wear track after SEM observations reveals that the debris removed by the friction effect are present at the first contact cycles between the antagonists and that the particle size is lower than $0.5 \mu \mathrm{m}$ (Fig. 11a). Thereby, some of the particles are ejected outside the contact zone, whereas the others remain trapped. Similar results were found in the literature (Ref 52). The particle forms a third body, which participates to kinematic readjustment of the contact (Fig. 11b). The transition period is reached when the pull-off flow of particles becomes steady.

3.2.3.2 Quantitative and Qualitative Study of the Wear Behavior. The surface wear quantitative study of the tested samples after friction tests was carried out based on the wear track profile analyses for the films deposited on AISI 4140 steel substrates. The measured profiles were put together, and an average profile was determined from the worn area for each of the studied coatings and for the substrate base material. The wear volume is determined with a $3 \mathrm{D}$ optical profilometer. Figure 12(a) shows the 3D wear track profile obtained on the $\mathrm{PVD}_{2}$ coating and Fig. 12(b) shows the attachment of the debris on the alumina ball after the same test. This reflects the low amount of material transferred from the sample to the ball.

Figure 13 shows the wear volumes evolution $\left(V_{f}\right.$ : wear volume of the film and $V_{s}$ : wear volume of the AISI4140 substrate). The multilayers with a $\mathrm{Cr}$ underlayer at low residual stresses have lower wear volumes. Indeed, the $\mathrm{V}_{f}$ value is lower for the $\mathrm{PVD}_{2}$ coating compared to the $\mathrm{PVD}_{1}$ coating and $\mathrm{V}_{f}$ for $\mathrm{PVD}_{6}$ coating is also lower compared with $\mathrm{PVD}_{5}$ coating. On the other hand, when a $\mathrm{Cr}$ underlayer is added and developed with maximum stresses, the multilayer has a lower wear resistance as shown with the increase in wear volume ( $V_{f}$ for $\mathrm{PVD}_{3}<V_{f}$ for $\mathrm{PVD}_{4}$ ). Therefore, it is necessary to avoid the $\mathrm{Cr}$ layer with maximum residual stresses. The amount of material removed from the film and substrate was determined separately. Comparing $\mathrm{PVD}_{1}$ to $\mathrm{PVD}_{2}$, both produced under low residual stresses, it is noteworthy that the second one has a good wear resistance due to the presence of a $\mathrm{Cr}$ underlayer

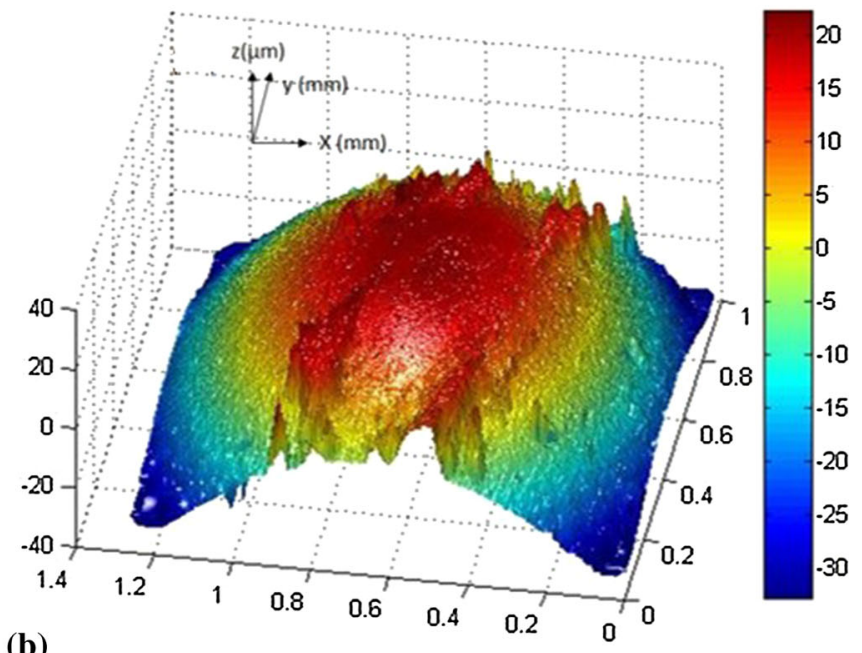

(b)

providing a good adhesion with the substrate. Concerning the two films produced under high residual stresses, $\mathrm{PVD}_{3}$ and $\mathrm{PVD}_{4}$, a good substrate adhesion of the $\mathrm{CrN}$ transition layer improves the wear resistance of the $\mathrm{PVD}_{3}$ coating. Furthermore, when the stress level is different in the single layers of the entire film, the obtained results are consistent and innovative. Indeed, the best wear resistance is reached for the multilayer synthesized with a $\mathrm{Cr}$ underlayer at low residual stresses $\left(\mathrm{PVD}_{6}\right)$, compared to the one with high residual stresses $\left(\mathrm{PVD}_{4}\right)$. These two coatings are significantly better in terms of wear when compared to the $\mathrm{PVD}_{5}(\mathrm{CrN}$ underlayer grown with low stresses and CrAlN with high residual stresses).

The residual stress level combination (as in $\mathrm{PVD}_{5}$ and $\mathrm{PVD}_{6}$ ) results in a good wear resistance. The level of residual stresses in these multilayers is generally moderated (the residual stresses in the underlayer are considered to be minimal, while those in the other layers are maximal) and the adhesion with the substrate is high. Although the as-deposited films $\left(\mathrm{PVD}_{5}\right.$ and $\left.\mathrm{PVD}_{6}\right)$ had similar COF during dry sliding tests, the morphologies of the wear tracks of this kind of films were quite different (Fig. 14). The analysis of the wear tracks indicates the highest residual stressed coatings delamination and the cracks appearance within the wear track. Usually, the stresses in a coating may induce crack propagation and, consequently, produce the plastic deformation by the local coating fracture as in brittle cracking. As a consequence, the wear rate of the coating may increase as shown in (Ref 53).

Thereby, two simple models can be distinguished to indicate the tribological behavior of the $\mathrm{Cr} / \mathrm{CrN} / \mathrm{CrAlN}$ and $\mathrm{CrN} / \mathrm{CrAlN}$ films. The $\mathrm{Cr} / \mathrm{CrN} / \mathrm{CrAlN}$ coating presents a smooth worn surface with great fragment removal efficiency. The debris were eliminated instantly from the contact track and accumulated at the wear track edges. However, for the CrN/CrAlN coating, there was a thick oxidized debris film developed inside the wear track on which the debris were subsequently formed and then gradually removed. The difference in wear morphology of these two types (i.e., $\mathrm{Cr} / \mathrm{CrN} / \mathrm{CrAlN}$ and $\mathrm{CrN} / \mathrm{CrAlN}$ ) of multilayers mainly results from the debris removal behaviors. Indeed, considering the fact that these two coatings have similar surface 
roughness, the wear difference can be attributed to the difference in the characteristics of debris as well as in the level of residual stresses. The results previously detailed indicate that coatings were oxidized during the wear test probably because of frictional heat (Ref 54). Generally, there is no significant difference in the tribological behavior of multilayer coating systems. This behavior is related to the type of oxides incorporated and formed during friction is similar for all films $\left(\mathrm{Cr}_{2} \mathrm{O}_{3}, \mathrm{FeO}_{2}\right.$ and $\left.\mathrm{Al}_{2} \mathrm{O}_{3}\right)$ (Ref 55, 56). This should lead to the same debris removal behavior between the coatings. It is recognized that the type of multilayers $\mathrm{Cr} / \mathrm{CrN} / \mathrm{CrAlN}$ and

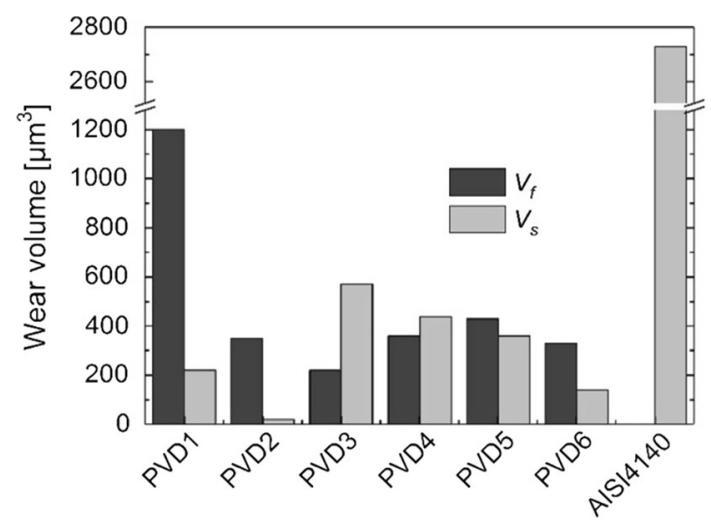

Fig. 13 Wear volume of the $\operatorname{PVD}_{\mathrm{i}}$ films $\left(V_{f}\right)$ and wear volume of AISI4140 substrate $\left(V_{s}\right)$. Duration of the test: $t=15 \mathrm{~min}$, normal force applied: $F_{n}=5 \mathrm{~N}$, speed: $v=8 \mathrm{~mm} \mathrm{~s}^{-1}$, amplitude of displacement: $\delta= \pm 2.5 \mathrm{~mm}$
$\mathrm{CrN} / \mathrm{CrAlN}$ shows the same oxidation resistance; the Al oxide films formed during high temperatures are expected to be an efficient thermal barrier as well as a lubricating layer (Ref 5557). Therefore, it can probably have a crucial role in the wear process and slightly affect the tribological behavior. In the light of these experimental investigations, it is noteworthy that the wear resistance of coatings depends significantly from their level of residual stresses, their tribological properties and chemical composition.

\section{Conclusion}

Characteristics and properties of $\mathrm{Cr}, \mathrm{CrN}$ and $\mathrm{CrAlN}$ monolayer coatings deposited by dual RF magnetron sputtering are investigated as a preliminary study. These results lead to the development of multilayer $\mathrm{CrN} / \mathrm{CrAlN}$ and $\mathrm{Cr} / \mathrm{CrN} / \mathrm{CrAlN}$ thin films with different levels of residual stresses in their constitutive layers. The physicochemical properties of these coatings are subsequently investigated. Reciprocating sliding wear tests were performed and compared to investigate the tribological properties of the multilayers. Observations and characterizations are focused on their tribological behavior, wear mechanisms and adhesion properties. The effect on the wear properties and oxidation were also subject of investigation. Several conclusions are given based on the observations and associated discussions:

1. The multilayers exhibit a prominent reflection along (200) and (111) planes corresponding to the cubic $\mathrm{CrN}$ phase,
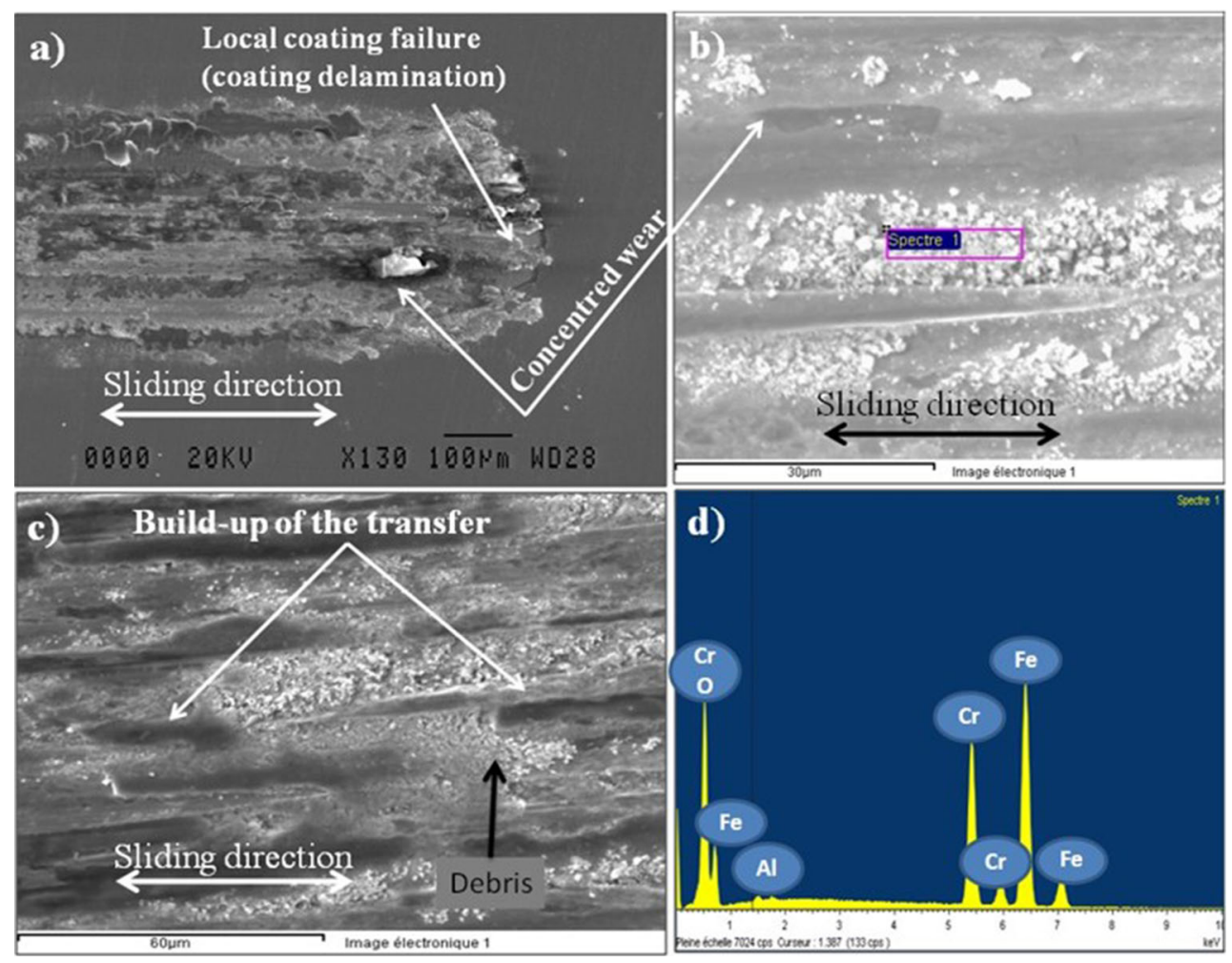

Fig. 14 SEM images of the (a) $\mathrm{PVD}_{5}$, (b) $\mathrm{PVD}_{6}$, (c) $\mathrm{PVD}_{6}$. PVDi films worn surfaces sliding against $\mathrm{Al}_{2} \mathrm{O}_{3}$ alumina ball and (d) EDS microanalyses of the debris (duration of the test: $t=15 \mathrm{~min}$, normal force applied: $F n=5 \mathrm{~N}$, speed: $v=8 \mathrm{~mm} \mathrm{~s}^{-1}$ and amplitude of displacement: $\delta= \pm 2.5 \mathrm{~mm}$ ) 
2. The residual stresses in the multilayers are lower than those of their single-layer components. This result is related to the physicochemical properties of the layer interface and the variation of the partial thickness,

3. The coatings present good adhesion to the substrate, especially the $\mathrm{Cr} / \mathrm{CrN} / \mathrm{CrAlN}$ one. This is due to the presence of the chromium underlayer. This layer reduces the stress extent between the substrate and the main film,

4. $\mathrm{Cr} / \mathrm{CrN} / \mathrm{CrAlN}$ multilayers show a sparsely better friction property and higher wear resistance (in particular $\mathrm{PVD}_{2}$ ) compared to $\mathrm{CrN} / \mathrm{CrAlN}$ multilayers developed without a $\mathrm{Cr}$ underlayer. However, $\mathrm{PVD}_{3}$ and $\mathrm{PVD}_{4}$ thin films prepared under high residual stresses suffered severe wear even when moderate normal loads were applied $\left(F_{n} \geq 5\right.$ $\mathrm{N})$. These wear are characterized by a combination of delamination, abrasive and oxidative wear,

5. The thin multilayers prepared with low residual stresses level are mainly characterized by concentrated wear. Other films, such as $\mathrm{PVD}_{6}$ prepared with combined residual stresses level (lower in $\mathrm{Cr}$, higher in $\mathrm{CrN}$ and CrAIN), show considerable improvement in debris removal of wear despite a lower thickness and better wear resistance under moderate normal loads.

\section{Acknowledgments}

The authors would like to thank Mr. Romain Fliti, Mr. Denis Lagadrillère for experimental support, Pr. Alain Iost and Pr. Luc Imhoff for helpful discussions and collaboration during this work.

\section{References}

1. A. Pilkington, S.J. Dowey, J.T. Toton, and E.D. Doyle, Machining with AlCr-Oxinitride Coated Cutting Tools, Tribol. Int., 2013, 65, p 303313

2. J. Heinrichs, J. Gerth, T. Thersleff, U. Bexell, M. Larsson, and U. Wiklund, Influence of Sliding Speed on Modes of Material Transfer as Steel Slides Against PVD Tool Coatings, Tribol. Int., 2013, 58, p 5564

3. S. PalDey and S.C. Deevi, Single Layer and Multilayer Wear Resistant Coatings of (Ti, Al) N: A Review, Mater. Sci. Eng. A, 2003, 342(1), p 58-79

4. Z. Li, P. Munroe, Z. Jiang, X. Zhao, J. Xu, Z. Zhou, J. Jiang, F. Fang, and Z. Xie, Designing Superhard, Self-Toughening CrAlN Coatings Through Grain Boundary Engineering, Acta Mater, 2012, 60(16), p 5735-5744

5. M. Cekada, P. Panjan, M. Macek, and P. Amid, Comparison of Structural and Chemical Properties of Cr-Based Hard Coatings, Surf. Coat. Technol., 2002, 151-152, p 31-35

6. G.S. Kim and S.Y. Lee, Microstructure and Mechanical Properties of AlCrN Films Deposited by CFUBMS, Surf. Coat. Technol., 2006, 201, p 4361-4366

7. I.M. Penttinen, A.S. Korhonen, E. Harju, M.A. Turkia, O. Forsen, and O. Ristolainen, Comparison of the Corrosion Resistance of TiN and (Ti, Al)N Coatings, Surf. Coat. Technol., 1992, 50, p 161-168

8. M. Vanstappen, B. Malliet, L. De Schepper, L.M. Stals, J.P. Celis, and J.R. Roos, Influence of Ti Intermediate Layer on Properties of Tin Coatings Deposited on Various Substrates, Surf. Eng., 1989, 5(4), p 305-310

9. G.A. Fontalvo, R. Daniel, and C. Mitterer, Interlayer Thickness Influence on the Tribological Response of bi-Layer Coatings, Tribol. Int., 2010, 43, p 108-112

10. C.A. Dobrzanski, M. Polok, P. Panjan, S. Bugliosi, and M. Adaniak, Improvement of Wear Resistance of Hot Work Steels by PVD Coatings Deposition, J. Mater. Process. Technol., 2004, 155-156, p 1995-2001
11. Y. Birol, Sliding Wear of CrN, AlCrN and AlTiN Coated AISI, H13 Hot Work Tool Steels in Aluminum Extrusion, Tribol. Int., 2013, 57, p 101-106

12. M. Okumiya and M. Griepentrog, Mechanical Properties and Tribological Behavior of TiN/CrAlN and CrN/CrAlN Multilayer Coatings, Surf. Coat. Technol., 1999, 112, p 123-128

13. B. Warcholinski, A. Gilewicz, and J. Ratajski, $\mathrm{Cr}_{2} \mathrm{~N} / \mathrm{CrN}$ Multilayer Coatings for Wood Machining Tools, Tribol. Int., 2011, 44, p 10761082

14. Y. Birol, High-Temperature Abrasive Wear Testing of Potential Tool Materials for Thixoforming of Steels, Tribol. Int., 2010, 43, p 22222230

15. M. Kawate, A.K. Hashimoto, and T. Suzuki, Oxidation Resistance of Cr1-xAlxN and Ti1-xAlxN Films, Surf. Coat. Technol., 2003, 165, p $163-167$

16. Y.C. Chim, X.Z. Ding, X.T. Zeng, and S. Zhang, Oxidation Resistance of TiN, CrN, TiAlN and CrAlN Coatings Deposited by Lateral Rotating Cathode Arc, Thin Solid Films, 2009, 517, p 4845-4849

17. M. Uchida, N. Nihira, A. Mitsuo, K. Toyoda, K. Kubota, and T. Aizawa, Friction and Wear Properties of CrAlN and CrVN Films Deposited by Cathodic Arc Ion Plating Method, Surf. Coat. Technol., 2004, 177-178, p 627-630

18. O. Knotek, F. Loffler, and H.-J. Scholl, Properties of Arc-Evaporated CrN and (Cr, Al)N Coatings, Surf. Coat. Technol., 1991, 45, p 53-58

19. M.-A. Djouadi, C. Nouveau, O. Banakh, R. Sanjinés, F. Lévy, and G. Nouet, Stress Profiles and Thermal Stability of CrxNy Films Deposited by Magnetron Sputtering, Surf. Coat. Technol., 2002, 151-152, p 510514

20. J.L. Mo and M.H. Zhu, Tribological Oxidation Behaviour of PVD Hard Coatings, Tribol. Int., 2009, 42, p 1758-1764

21. A.E. Reiter, V.H. Derflinger, B. Hanselmann, T. Bachmann, and B. Sartory, Investigation of the Properties of $\mathrm{Al}_{1-\mathrm{x}} \mathrm{Cr}_{\mathrm{x}} \mathrm{N}$ Coatings Prepared by Cathodic Arc Evaporation, Surf. Coat. Technol., 2005, 200, p 2114-2122

22. J. Sun, C. Sun, and Y. Wang, Effect of $\mathrm{Cr}$ Content on the Electrochemical Behavior of Low Chromium X65 Steel in $\mathrm{CO}_{2}$ Environment, Int. J. Electrochem. Sci., 2016, 11, p 8599-8611

23. A. Ben Cheikh Larbi and B. Tlili, Fretting Wear of Multilayered PVD TiAlCN/TiAlN/TiAl on AISI, 4140 Steel, Surf. Coat. Technol., 2006, 201, p 1511-1518

24. T.W. Clyne and S.C. Gill, Residual Stresses in Thermal Spray Coatings and Their Effect on Interfacial Adhesion, J. Therm. Spray Technol., 1996, 5, p 401-418

25. M. Ahlgren and H. Blomqvist, Influence of Bias Variation on Residual Stress and Texture in TiAlN PVD Coatings, Surf. Coat. Technol., 2005, 200, p 157-160

26. G.D. Quinn, P.L. Patel, and I. Lloyd, Effect of Loading Rate Upon Conventional Ceramic Microindentation Hardness, J. Res. Nat. Inst. Stand. Technol., 2002, 107, p 299-306

27. K. Rahmoun, A. Iost, V. Keryvin, G. Guillemot, and N.E. Chabane Sari, A Multilayer Model for Describing Hardness Variations of Aged Porous Silicon Low-Dielectric-Constant Thin Films, Thin Solid Films, 2009, 518, p 213-221

28. T. Ghrib, B. Tlili, C. Nouveau, Y. Benlatreche, M. Lambertin, N. Yacoubi, and M. Ennasri, Experimental Investigation of the Mechanical Micro Structural and Thermal Properties of Thin CrAIN Layers Deposited by PVD Technique for Various Aluminum Percentages, Phys. Proc., 2009, 2, p 1327-1336

29. F. Vaz, L. Rebouta, Ph. Goudeau, J.P. Rivière, E. Schäffer, G. Kleer, and M. Bodmann, Residual Stress States in Sputtered $\mathrm{Ti}_{1-\mathrm{x}} \mathrm{Si}_{\mathrm{x}} \mathrm{N}_{\mathrm{y}}$ Films, Thin Solid Films, 2002, 402, p 195-202

30. G. Dehm, D. Weiss, and E. Arzt, In Situ Transmission Electron Microscopy Study of Thermal-Stress Induced Dislocations in a Thin $\mathrm{Cu}$ Film Constrained by a Si Substrate, Mat. Sci. Eng., 2001, A309310, p 468-472

31. B. Tlili, N. Mustapha, C. Nouveau, Y. Benlatreche, G. Guillemot, and M. Lambertin, Correlation Between Thermal Properties and Aluminum Fractions in CrAlN Layers Deposited by PVD Technique, Vacuum, 2010, 84, p 1067-1074

32. C. Nouveau, B. Tlili, H. Aknouche, Y. Benlatreche, and B. Patel, Comparison of CrAlN Layers Obtained with One (CrAl) or Two Targets (Cr and Al) by Magnetron Sputtering, Thin Solid Films, 2012, 520, p 2932-2937 
33. G.G. Stoney, The Tension of Metallic Films Deposited by Electrolysis, Proc. R. Soc. Lond. A, 1909, 82, p 172-175

34. A. Mézin, Coating Internal Stress Measurement Through the Curvature Method: A Geometry-Based Criterion Delimiting the Relevance of Stoney's Formula, Surf. Coat. Technol., 2006, 200, p 5259-5267

35. K.H. Raveesha, K. Kumar, and B.K. Prasad, On Alternative Methods of Determining Radius of Curvature Using Newton's Rings Set Up, Int. Lett. Chem. Phys. Astron., 2015, 48, p 27-31

36. W.J. Meng, J.A. Sell, T.A. Perry, L.E. Rehn, and P.M. Baldo, Growth of Aluminum Nitride Thin Films on Si (111) and Si (001): Structural Characteristics and Development of Intrinsic Stresses, J. Appl. Phys., 1994, 75, p 3446-3455

37. D.R. McKenzie, D. Muller, and B.A. Pailthorpe, Compressive-StressInduced Formation of Thin-Film Tetrahedral Amorphous Carbon, Phys. Rev. Lett., 1991, 67, p 773

38. C. Quaeyhaegens, G. Knyt, J. D'Haen, and L.M. Stals, Experimental Study of the Growth Evolution from Random Towards a (111) Preferential Orientation of PVD TiN Coatings, Thin Solid Films, 1995, 258, p 170-173

39. W.J. Meng, J.A. Sell, and T.A. Perry, Measurement of Intrinsic Stresses During Growth of Aluminum Nitride Thin Films by Reactive Sputter Deposition, J. Appl. Phys., 1993, 74(4), p 2411-2414

40. C. Nouveau. Etude de revêtements durs (CrxNy) obtenus par méthodes PVD: réalisation et caractérisations, applications à l'usinage du bois. Thèse de doctorat n ${ }^{\circ}$ 21-2001, CER ENSAM Cluny, France

41. L. Chekour, C. Nouveau, A. Chala, C. Labidi, N. Rouag, and M.A. Djouadi, Growth Mechanism for Chromium Nitride Films Deposited by Magnetron and Triode Sputtering Methods, Surf. Coat. Technol., 2005, 200, p 241-244

42. H. Holleck and H. Schulz, Preparation and Behaviour of WearResistant $\mathrm{TiC} / \mathrm{TiB}_{2}, \mathrm{TiN} / \mathrm{TiB}_{2}$ and $\mathrm{TiC} / \mathrm{TiN}$ Coatings with High Amounts of Phase Boundaries, Surf. Coat. Technol., 1988, 36, p 707-714

43. P. Panjan, B. Navinsek, A. Cvelbar, and I. Milosev, Oxidation of TiN, $\mathrm{ZrN}, \mathrm{TiZrN}, \mathrm{CrN}, \mathrm{TiCrN}$ and TiN/CrN Multilayer Hard Coatings Reactively Sputtered at Low Temperature, Thin Solid Films, 1996, 282, p 298-301

44. A. Gilewicz and B. Warcholinski, Tribological Properties of $\mathrm{CrCN} / \mathrm{CrN}$ Multilayer Coatings, Tribol. Int., 2014, 80, p 34-40

45. Q. Wang, F. Zhoub, and J. Yana, Evaluating Mechanical Properties and Crack Resistance of CrN, CrTiN, CrAlN and CrTiAlN Coatings by
Nanoindentation and Scratch Tests, Surf. Coat. Technol., 2016, 285, p 203-213

46. Y.X. Wang, S. Zhang, J.-W. Lee, W.S. Lew, and B. Li, Influence of Bias Voltage on the Hardness and Toughness of CrAlN Coatings via Magnetron Sputtering, Surf. Coat. Technol., 2012, 206, p 5103-5107

47. I. Rahil, Élaboration et caractérisation de revêtements à base de nitrure de Chrome, carbonitrure et carbure de Titane élaborés par pulvérisation magnétron. Thèse de doctorat $\mathrm{n}^{\circ} 432-2013$, CER ENSAM Cluny, France

48. Y.C. Chim, X.Z. Ding, X.T. Zeng, and S. Zhang, Oxidation Resistance of TiN, CrN, TiAlN and CrAlN Coatings Deposited by Lateral Rotating Cathode Arc, Thin Solid Films, 2009, 517, p 4845-4849

49. J. Musil and H. Hrubý, Superhard Nanocomposite $\mathrm{Ti}_{1-x} \mathrm{Al}_{\mathrm{x}} \mathrm{N}$ Films Prepared by Magnetron Sputtering, Thin Solid Films, 2000, 365, p 104-109

50. A.G. Evans, J.W. Hutchinson, and Y. Wei, Interface Adhesion: Effects of Plasticity and Segregation, Acta Mater., 1999, 47, p 4093-4113

51. E. de Wit, B. Blanpain, L. Froyen, and J.-P. Celis, The Tribochemical Behaviour of TiN-Coatings During Fretting Wear, Wear, 1998, 217, p 215-224

52. B. Alemón, M. Flores, W. Ramírez, J.C. Huegel, and E. Broitman, Tribocorrosion Behavior and Ions Release of CoCrMo Alloy Coated with a TiAlVCN/CN $\mathrm{C}_{\mathrm{x}}$ Multilayer in Simulated Body Fluid Plus Bovine Serum Albumin, Tribol. Int., 2015, 81, p 159-168

53. A.A. Voevodin, C. Rebholz, J.M. Schneider, P. Stevenson, and A. Matthews, Wear Resistant Composite Coatings Deposited by Electron Enhanced Closed Field Unbalanced Magnetron Sputtering, Surf. Coat. Technol., 1995, 73, p 185-197

54. Y. Mu, M. Liu, and Y. Zhao, Carbon Doping to Improve the High Temperature Tribological Properties of VN Coating, Tribol. Int., 2016, 97, p 327-336

55. H. Hasegawa, M. Kawate, and T. Suzuki, Effects of Al Contents on Microstructures of $\mathrm{Cr}_{1-\mathrm{x}} \mathrm{Al}_{\mathrm{xN}}$ and $\mathrm{Zr}_{1-\mathrm{x}} \mathrm{Al}_{\mathrm{x}} \mathrm{N}$ Films Synthesized by Cathodic Arc Method, Surf. Coat. Technol., 2005, 200, p 2409-2413

56. S. Tao, Z. Yin, X. Zhou, and C. Ding, Sliding Wear Characteristics of Plasma-Sprayed $\mathrm{Al}_{2} \mathrm{O}_{3}$ and $\mathrm{Cr}_{2} \mathrm{O}_{3}$ Coatings Against Copper Alloy Under Severe Conditions, Tribol. Int., 2010, 43, p 69-75

57. J. Nohava, P. Dessarzin, P. Karvankova, and M. Morstein, Characterization of Tribological Behavior and Wear Mechanisms of Novel Oxynitride PVD Coatings Designed for Applications at High Temperatures, Tribol. Int., 2015, 81, p 231-239 